\title{
Moderate alkali-thermophilic ethanologenesis by locally isolated Bacillus licheniformis from Pakistan employing sugarcane bagasse: a comparative aspect of aseptic and non-aseptic fermentations
}

\author{
Qurat-ul-Ain Ahmad ${ }^{1 *} \mathbb{C}$, Shang-Tian Yang ${ }^{2}$, Maleeha Manzoor ${ }^{3}$ and Javed Iqbal Qazi ${ }^{1}$
}

\begin{abstract}
Background: Biofuels obtained from first-generation (1G) sugars-starch streams have been proven unsustainable as their constant consumption is not only significantly costly for commercial scale production systems, but it could potentially lead to problems associated with extortionate food items for human usage. In this regard, biofuels' production in alkali-thermophilic environs from second-generation (2G) bio-waste would not only be markedly feasible, but these extreme conditions might be able to sustain aseptic fermentations without spending much for sterilization.

Results: Present investigation deals with the valuation of ethanologenic potential of locally isolated moderate alkalithermophilic fermentative bacterium, Bacillus licheniformis KU886221 employing sugarcane cane bagasse (SCB) as substrate. A standard 2-factor central composite response surface design was used to estimate the optimized cellulolytic and hemicellulolytic enzymatic hydrolysis of SCB into maximum fermentable sugars. After elucidation of optimized levels of fermentation factors affecting ethanol fermentation using Taguchi OA L27 (3^13) experimental design, free cell batch culture was carried out in bench-scale stirred-tank bioreactor for ethanol fermentation. Succeeding fermentation modifications included subsequent substrate addition, immobilized cells fibrous-bed bioreactor (FBB) incorporation to the basic setup, and performance of in situ gas stripping for attaining improved ethanol yield. Highest ethanol yield of $1.1406 \mathrm{~mol}$ ethanol/mol of equivalent sugars consumed was obtained when gas stripping was performed during fed-batch fermentation involving FBB under aseptic conditions. Despite the fact that under nonaseptic conditions, 30.5\% lesser ethanol was formed, still, reduced yield might be considered influential as it saved the cost of sterilization for ethanol production.
\end{abstract}

Conclusion: Effectual utilization of low-priced abundantly available lignocellulosic waste sugarcane bagasse under non-aseptic moderate alkali-thermophilic fermentation conditions as directed in this study has appeared very promising for large-scale cost-effective bioethanol generation processes.

Keywords: 2G ethanologenesis, Lignocellulosic ethanol fermentation, Fibrous-bed bioreactor, Gas stripping, Central composite design, Taguchi orthogonal array

\footnotetext{
*Correspondence: quratulainahmad2011@gmail.com

1 Department of Zoology, University of the Punjab, Lahore, Pakistan

Full list of author information is available at the end of the article
} 


\section{Background}

Energy is regarded as the lifeline of economic amelioration. Bio-conversion of different organic wastes to bioenergy fuels via microbial fermentations is being looked upon seriously all over the world due to its sustainable productive potential. Consequently, valorization of second-generation (2G) lignocellulosic biomass (LCB) through bio-fermentation employing extremophiles is the strategic tool leading to sustainable process development for biofuels' generation. Biofuels are principally derived from plant biomass through microbial fermentations [1].

$2 \mathrm{G}$ biofuels productions primarily address the renewable, non-food competing biomass-to-biofuels conversions that might mitigate further environmental deterioration, already reached to an alarmingly significant level in the form of pollution and global warming [2].

LCB (primarily comprises of cellulose, hemicellulose, and lignin) is first degraded into long-chain polysaccharides and then into their corresponding monosaccharides [3-5].

Several pretreatment methodologies for the separation of cellulose and hemicelluloses from lignin have been projected including acidic methods [6], hydrothermal processing [7], mild alkaline methods [6], oxidative methods [8], ionic liquid method [9], and chemical pulping methods $[10,11]$. Unlike acid and hydrothermal pretreatments, alkaline pretreatment results not only in reduced hemicellulose solubilization but also lesser fermentation inhibitors production [6]. It results in increased enzymatic convertibility of accessible cellulose and hemicellulose into fermentable sugars, thus overcoming the biomass recalcitrance that poses itself as a prime impediment for LCB saccharification and subsequent fermentation into ethanol at large $[12,13]$.

Considerable efforts are being done worldwide to develop cost-competitive processes for biofuels production [1]. In this regard, sugarcane bagasse (SCB) represents itself as potential valuable $2 \mathrm{G}$ fuels' feed, adequately rich in energy for fermentative processes. By exploiting extremophiles in bio-fermentations, the risk of microbial contamination(s) decreases, and thus, aseptic environment may be maintained with fewer efforts $[14,15]$. Hence, the use of fermentative extremophiles may prove feasible and cost-competitive while developing biofuels production processes under non-aseptic conditions in near future [16].

Acetone-butanol-ethanol (ABE) productions from sugar-starch substrates are well renowned. Research is being targeted to develop ABE fermentation processes associated with high yields, titers, and productivities utilizing $2 \mathrm{G}$ agro-industrial wastes $[17,18]$.
This study mainly focuses on the application of locally isolated alkali-thermophilic bacterium Bacillus licheniformis KU886221 for ethanol production employing SCB as substrate. It is anticipated that bio-fermentations utilizing agro-industrial LCB, when establish, will ultimately lead to efficient waste reduction, low $\mathrm{CO}_{2}$ emission, and cost-effective production of high-grade liquid fuels as ethanol.

\section{Methods}

Isolation, screening, and characterization of alkali-thermophilic ethanologenic bacteria

Alkali-thermophilic bacteria were isolated from the soil sampled from the vicinity of hot water effluent near Balkasar oil refinery, Chakwal, Pakistan, where the mud temperature was $50-55{ }^{\circ} \mathrm{C}$ with $\mathrm{pH}$ ranging 9-10. The samples were incubated anaerobically at $45{ }^{\circ} \mathrm{C}(\mathrm{pH} 9)$ for 5 days in fermentation medium FM1 containing $\mathrm{g} / \mathrm{L}$, glucose; 20, $\mathrm{KH}_{2} \mathrm{PO}_{4} ; 1, \mathrm{MgSO}_{4} ; 0.1, \mathrm{CaCl}_{2} \cdot 2 \mathrm{H}_{2} \mathrm{O} ; 0.1$, yeast extract; 0.5 and peptone; 15 . Further enrichment of the cultures was done in the same medium substituting $2 \%$ glucose with $5 \%$ sugarcane bagasse (SCB). On the bases of conspicuous growth on solidified fermentation medium, 34 isolates were further processed for screening of fermentative ethanologens. The initial selection of the eight ethanologenic bacteria was accomplished through the improved method of Snell and Snell [19].

For quantifying their ethanologenic potential, $50 \mathrm{~mL}$ of medium in $150 \mathrm{~mL}$ serum bottle was made for each isolate and purged with nitrogen for $8 \mathrm{~min}$ to remove oxygen. Then immediately, the serum bottles were firmly capped with rubber stopper and sealed with aluminum rings. These bottles were autoclaved for $30 \mathrm{~min}$ at $121^{\circ} \mathrm{C}$. After cooling, the bottles were inoculated using 5\% inoculum in $5 \mathrm{~mL}$ syringe under aseptic conditions. Gas chromatograph (Shimadzu GC-2014) used was equipped with flame ionization detector (FID) and a $30 \mathrm{~m}$ fused silica column (0.25 $\mathrm{m}$ film thickness and $0.25 \mathrm{~mm}$ ID, Stabilwax-DA). Nitrogen was used as carrier gas at $1.47 \mathrm{~mL} / \mathrm{min}$ (linear velocity: $35 \mathrm{~cm} / \mathrm{s}$ ). For analysis, $1 \mathrm{~mL}$ of sample was taken in Eppendorf and centrifuged at 13,000 rpm for $10 \mathrm{~min}$. Clear supernatant was transferred to another Eppendorf and diluted 20 times before injecting to $\mathrm{GC}$ with a GC internal standard buffer solution $(0.5 \mathrm{~g} / \mathrm{L}$ isobutanol, $1 \%$ phosphoric acid and $0.1 \mathrm{~g} / \mathrm{L}$ isobutyric acid (used for acidification). The column temperature was held at $80{ }^{\circ} \mathrm{C}$ for $3 \mathrm{~min}$, raised to $150{ }^{\circ} \mathrm{C}$ at a rate of $30^{\circ} \mathrm{C} / \mathrm{min}$, and held at $150{ }^{\circ} \mathrm{C}$ for $3.7 \mathrm{~min}$. Both the injector and detector were set at $250{ }^{\circ} \mathrm{C}$. Then, with the help of GC auto-injector (AOC20i Shimadzu), $1 \mu \mathrm{L}$ sample was injected for analysis. The bacterial isolate ML-07 was found to produce highest ethanol and selected to further study the fermentation kinetics for bench-scale bioethanol fermentation. 
Isolate ML-07 was characterized genotypically following its $16 \mathrm{~S}$ rRNA gene sequencing. The DNA sequence was assembled with BioEdit Sequence Alignment Editor (version 7.2.5). Homology finding of the isolate was accomplished using BLAST [20]. 16S rRNA gene sequence was finally submitted to GenBank for procuring accession numbers.

\section{Study of ethanologenesis employing different sugars and nitrogen sources in fermentation medium}

Potential of the ethanologenic bacterium to ferment different sugars (glucose, xylose, mannose, galactose, arabinose, and cellulose) was evaluated by incorporating them as sole carbon source in FM1, whereas the potential of corn steep liquor as nitrogen source was evaluated by replacing $20 \mathrm{~g}$ of CSL with peptone + yeast extract in FM1 medium. Ethanol production by isolation of ML-07 was measured using gas chromatograph after 3 days of incubation at $45^{\circ} \mathrm{C}(\mathrm{pH} 9)$.

\section{SCB hydrolysis}

SCB provided by Ohio State University, "Columbus Ohio", was hydrolyzed chemically as well as enzymatically.

\section{Chemical hydrolysis of SCB}

SCB were pretreated differently with varying concentrations of pretreatment chemicals (sulfuric acid, phosphoric acid, hydrochloric acid, and sodium hydroxide). For every pretreatment, the solid-to-liquid ratio was kept 1:12 and autoclaved for $30 \mathrm{~min}$. The cooled pretreated biomasses were immediately separated into liquid and solid fractions by vacuum filtration using Whatman No. 1 filter paper. The solid fraction was re-suspended in water and filtered three times to neutralize the $\mathrm{pH}$ and dried at $60{ }^{\circ} \mathrm{C}$ until the dried biomass weight became constant.

The compositions of the raw and pretreated SCB were determined by a standard analysis procedure, which was modified by the National Renewable Energy Laboratory (NREL) analytic methods [21]. The acid(s) and alkaline pretreatments were compared with respect to biomass dissociation into sugars, acids, and phenolic compounds. These components were quantified by high-performance liquid chromatography (HPLC) equipped with Bio-Rad HPX-87H column at $65{ }^{\circ} \mathrm{C}$ and a refractive index detector (Shimadzu RID-10A). The eluent (mobile phase) was $\mathrm{H}_{2} \mathrm{SO}_{4}(0.5 \mathrm{mN})$ at $0.6 \mathrm{~mL} / \mathrm{min}$.

\section{Enzymatic hydrolysis of SCB}

The raw and pretreated SCB were suspended in $50 \mathrm{mM}$ citrate buffer ( $\mathrm{pH} \mathrm{5)}$ in separate containers in solid-toliquid ratio 1:8 and then hydrolyzed enzymatically with commercially available Cellic Ctec $2+$ Cellic Htec 2
Novozymes $(13.5+1.5 \mathrm{mg} / \mathrm{g})$. The enzymatic hydrolysis was done under sterilized conditions in 250-mL Erlenmeyer flasks at constant agitation (150 RPM) and $50{ }^{\circ} \mathrm{C}$ incubation temperature for $72 \mathrm{~h}$. The hydrolysates were analyzed for sugar contents using HPLC.

\section{Ethanologenesis employing pretreated SCB with/without enzymatic hydrolysis}

The effect of acid/alkali pretreatment on lignocellulosic biomass and successive enzymatic hydrolysis on ethanol fermentation was studied for selection of pretreatment methods (in their optimum concentrations) of SCB for maximum ethanol production. Differently pretreated SCB (in their optimum concentrations for maximum sugars' production) following with/without enzymatic hydrolysis were substituted with carbon source in fermentation medium. Ethanol produced by isolate ML-07 up to $72 \mathrm{~h}$ of fermentation was quantified by GC, whereas sugars consumption was measured using HPLC.

\section{Optimization of enzymatic hydrolysis by CCD}

The response surface methodology (RSM) was applied to study the effect of Cellic Ctec 2 and Cellic Htec 2 Novozymes on the hydrolysis of alkaline pretreated SCB. The experiments were carried out according to central composite $\left(2^{2}\right)$ non-factorial surface design in one block. The response was total sugar contents (glucose and xylose) of pretreated SCB hydrolysate. The Statistica software (version 6.0) from Stat Soft, Inc. was used to design and statistically analyze the experiment. For the design model, five different coded levels for each variable were used: $1.41,-1,0$ (center) and $+1,+1.41$. The designs of all 11 experiments were performed in duplicates and the data produced were the mean value of the results. The secondorder polynomial model was constructed using the CCD.

\section{Experimental design for optimization of fermentation using Taguchi orthogonal array (OA)}

Taguchi OA method was used to design the experiment for optimization of fermentation parameters for ethanol production. For this purpose, experiment was designed by Taguchi OA L27 $\left(3^{\wedge} 13\right)$ of Design Expert software (version 8) to optimize six factors at three levels. The factors included three medium components including alkali treated $\mathrm{SCB}$ hydrolysate $(\mathrm{SCBH})$ derived from alkaline pretreated SCB (after enzymatic hydrolysis), corn steep liquor $(\mathrm{CSL})$, sodium chloride $(\mathrm{NaCl})$, incubation temperature, incubation $\mathrm{pH}$, and incubation time. Taguchi OA L27 represents the 27 experimental trials/ runs, while each run consisted of a certain blend of levels to which the factors were fixed. These combinations were obtained by crossing of the factors with particular 
levels. These 27 runs trials were performed in duplicates using $150 \mathrm{~mL}$ serum bottles and the averages of obtained results were statistically investigated for the analysis of variance (ANOVA).

\section{Fermentation in bioreactor}

The optimized conditions of fermentation factors were further scrutinized in bench-scale stirred-tank bioreactor under controlled $\mathrm{pH}$, temperature, and agitation (140 RPM) in aseptic environment. FM2 fermentation medium was prepared by substituting the optimized amounts of three medium components elucidated by Taguchi OA experimental design to study the fermentation kinetics in bioreactor. The setup of fermentor is shown in Fig. 1.

The seed culture was prepared in $150 \mathrm{~mL}$ serum bottle under optimized conditions of fermentation for $48 \mathrm{~h}$ and was inoculated in $1.5 \mathrm{~L}$ fermentation medium in bioreactor. The samples were taken periodically after every $12 \mathrm{~h}$ and analyzed for ethanol fermentation with GC and substrate utilization with HPLC and for O.D. with spectrophotometer (Shimadzu, Columbia, MD, UV-16-1).

\section{Immobilized-cell fermentation in fibrous-bed bioreactor}

(FBB)

To study the effect of cell immobilization on fermentation kinetics, FBB was attached with the stirred-tank bioreactor (Fig. 2) at $24 \mathrm{~h}$ when the optical density of the cell suspension was above 0.6. FBB was a glass vessel whose column was packed with spirally intricate fibrous matrix to immobilize the cells $[22,23]$.

The fermentation broth containing the cells was pumped into the FBB top from the fermentor and sent out from the bottom of FBB back into the fermentor. This allowed the broth cells to attach and immobilize on the fibrous matrix of FBB. Fermentation kinetics of fed-batch bioreactor involving FBB was studied at regular intervals of $12 \mathrm{~h}$ until the culture stopped consuming substrate/ producing ethanol.

\section{Downstream product recovery via gas stripping}

For ethanol recovery, gas stripping was done at the end of fermentation for $3 \mathrm{~h}$ via recycling the fermentation gases produced during fermentation through culture medium. Gas stripping was done through the fermentor

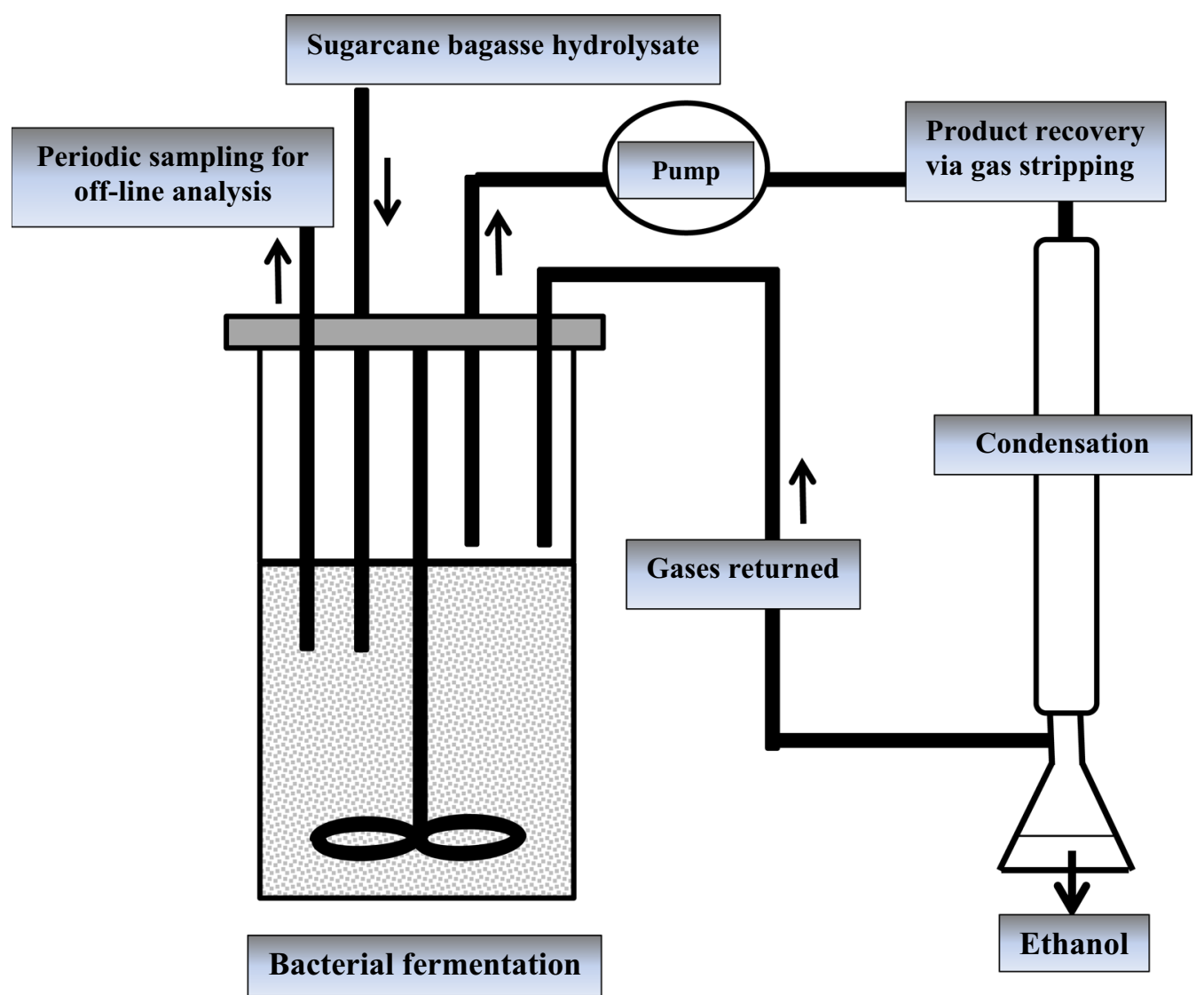

Fig. 1 Simplified process design for second-generation ethanol fermentation from biomass and downstream product recovery by in situ gas stripping 


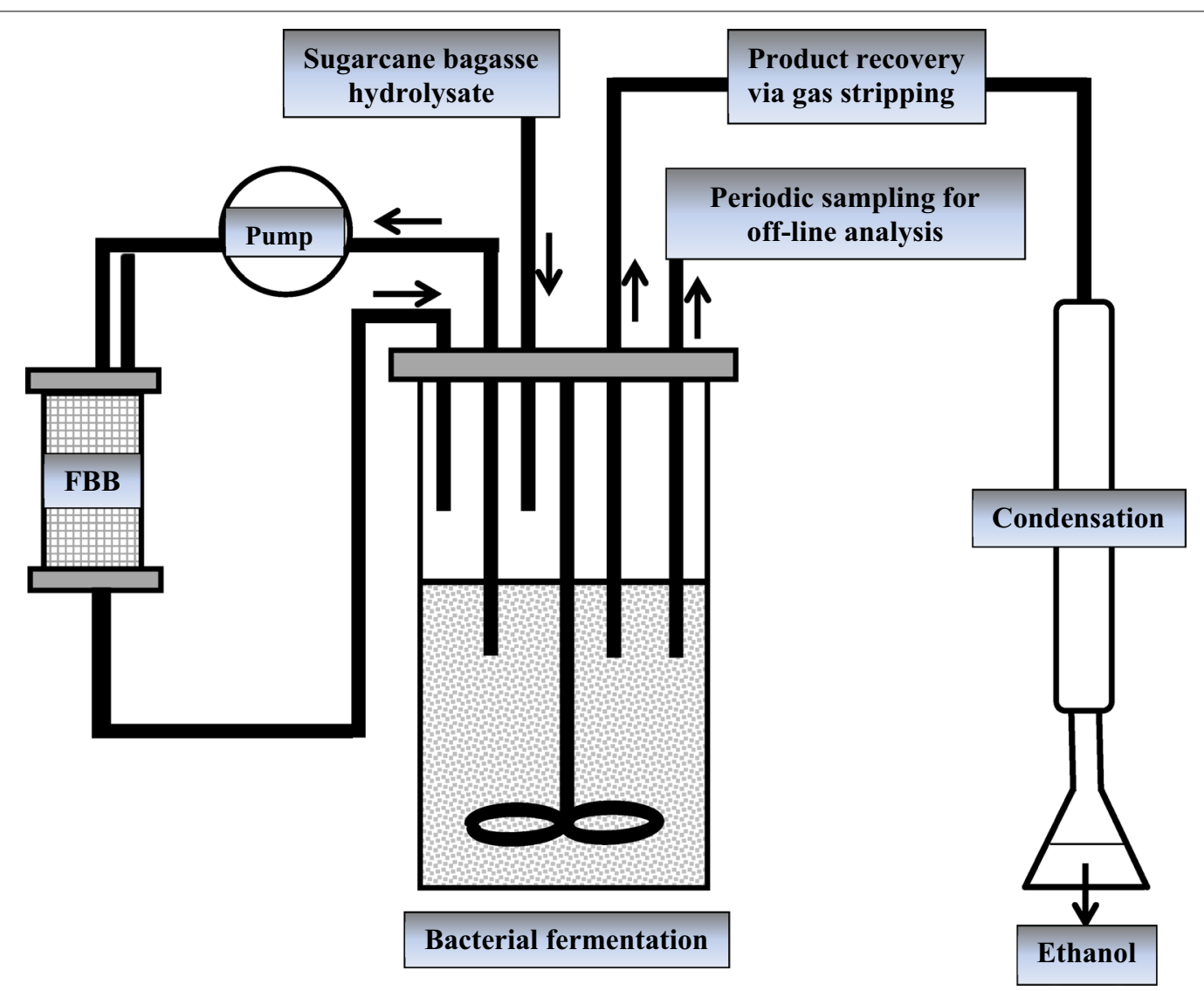

Fig. 2 Simplified process design for second-generation ethanol fermentation involving fibrous-bed bioreactor (FBB) from biomass and downstream product recovery by in situ gas stripping

to selectively strip the fermentation products (acetone, butanol, and ethanol) from fermentor broth. Detailed description for the setup and operation of the integrated system has been given previously $[24,25]$. The condensate was analyzed with GC for stripped fermentation products.

\section{Effect of ethanol removal on fermentation}

To diminish the effect of ethanol on productivity, gas stripping was also done during the fermentation (at $60 \mathrm{~h}$ ) when the ethanol concentration was above $10.0 \mathrm{~g} / \mathrm{L}$. The ethanol yield, titer, and productivity along with substrate utilization were noted during fed-batch fermentation involving FBB and gas stripping. The condensate obtained as a result of $6 \mathrm{~h}$ of gas stripping ( $3 \mathrm{~h}$ gas stripping at $60 \mathrm{~h}$ of fermentation and then $3 \mathrm{~h}$ of gas stripping at the end of fermentation (at $120 \mathrm{~h}$ ) was analyzed with GC.

\section{Bioethanol production under non-aseptic conditions}

Fermentation kinetics of the fed-batch fermentation involving FBB was finally studied under non-aseptic conditions. The ethanol yield, titer, and productivity along with substrate utilization during fermentation under non-aseptic conditions were noted. Gas stripping was done at the end of fermentation for $3 \mathrm{~h}$. The condensate was analyzed with GC for stripped fermentation products.

\section{Results}

Selection of ethanologenic alkali-thermophilic bacteria Of the 34 initially selected isolates based on their ethanol production, as assessed by Snell and Snell's modified method or ethanol quantification, eight were selected for further study. Ethanol production of isolate ML-07 was found to be significantly greater $(P<0.05)$ accounting $3.65 \mathrm{~g} / \mathrm{L}$, and therefore, it was selected for further study focusing on fermentation kinetics for highest production of ethanol. The gas chromatography analysis of the fermentation products also revealed that isolate ML-07 was the best ethanologenic bacteria producing $2.32 \mathrm{~g} / \mathrm{L}$ ethanol amongst all other isolates.

\section{Genotypic identification of bacterial isolate}

The isolate ML-07 was characterized on the basis of 16 s RNA gene sequencing. It was accordingly identified 
as a mild alkali-thermophilic strain of B. licheniformis. 16S rRNA gene sequences were submitted to GenBank for procuring with the accession number KU886221 assigned to this isolate.

\section{Ethanologenesis employing different sugars and nitrogen sources in fermentation medium}

The investigation on ethanologenic potential of B. licheniformis KU886221 to ferment different sugars directed that the strain has the ability to produce $5.6,4.4$, and $2.23 \mathrm{~g} / \mathrm{L}$ ethanol employing glucose, xylose, and cellulose as carbon source, respectively, in the fermentation medium. Moreover, substitution of corn steep liquor in FM1 medium for peptone + yeast extract improved ethanol production to 5.75 from $5.57 \mathrm{~g} / \mathrm{L}$ in the FM1 medium.

\section{Chemical hydrolysis of sugarcane bagasse}

Compositions of control and pretreated bagasse are shown in Fig. 3. Analysis shows that pretreatment with $2 \% \mathrm{H}_{2} \mathrm{SO}_{4}, 3 \% \mathrm{H}_{3} \mathrm{PO}_{4}$, and $1 \% \mathrm{HCl}$ resulted in comparable cellulose enrichment and xylan removal $(P<0.05)$, whereas with $1 \mathrm{~N} \mathrm{NaOH}$, statistically highest yields of cellulose and xylan were obtained.

\section{Enzymatic hydrolysis of sugarcane bagasse}

The pretreated SCB were further hydrolyzed enzymatically and studied for release of sugar contents (Fig. 4).
After enzymatic hydrolysis, SCB pretreated with $2 \%$ $\mathrm{H}_{2} \mathrm{SO}_{4}, 3 \% \mathrm{H}_{3} \mathrm{PO}_{4}$, and $1 \% \mathrm{HCl}$ released significantly increased levels of glucose, whereas SCB pretreated with $1 \mathrm{~N} \mathrm{NaOH}$ released cumulatively highest total sugars consisting glucose + xylose after enzymatic hydrolysis compared to other pretreatment methods $(P<0.05)$.

\section{Ethanologenesis after SCB hydrolysis by B. licheniformis KU886221}

SCB pretreated with $2 \% \mathrm{H}_{2} \mathrm{SO}_{4}, 3 \% \mathrm{H}_{3} \mathrm{PO}_{4}, 1 \% \mathrm{HCl}$, and $1 \mathrm{~N} \mathrm{NaOH}$ were selected for ethanol production using B. licheniformis KU886221. The fermentation was carried out on FM2 medium modified by replacing SCB with selected pretreated SCB $(100 \mathrm{~g} / \mathrm{L})$ following without/with enzymatic hydrolysis. When differently pretreated SCB without enzymatic hydrolysis were used, it was found that statistically higher ethanol was produced in which $1 \mathrm{~N} \mathrm{NaOH}$ treated SCB was employed as carbon source in the fermentation medium (Table 1). Whereas, $32.89 \%$ more ethanol was produced when alkaline pretreated $\mathrm{SCBH}$ following enzymatic hydrolysis was employed as fuel's feed (Table 2) compared to alkaline pretreated SCB without enzymatic hydrolysis. All experiments were performed in triplicates in $150 \mathrm{~mL}$ serum bottles under anaerobic conditions.
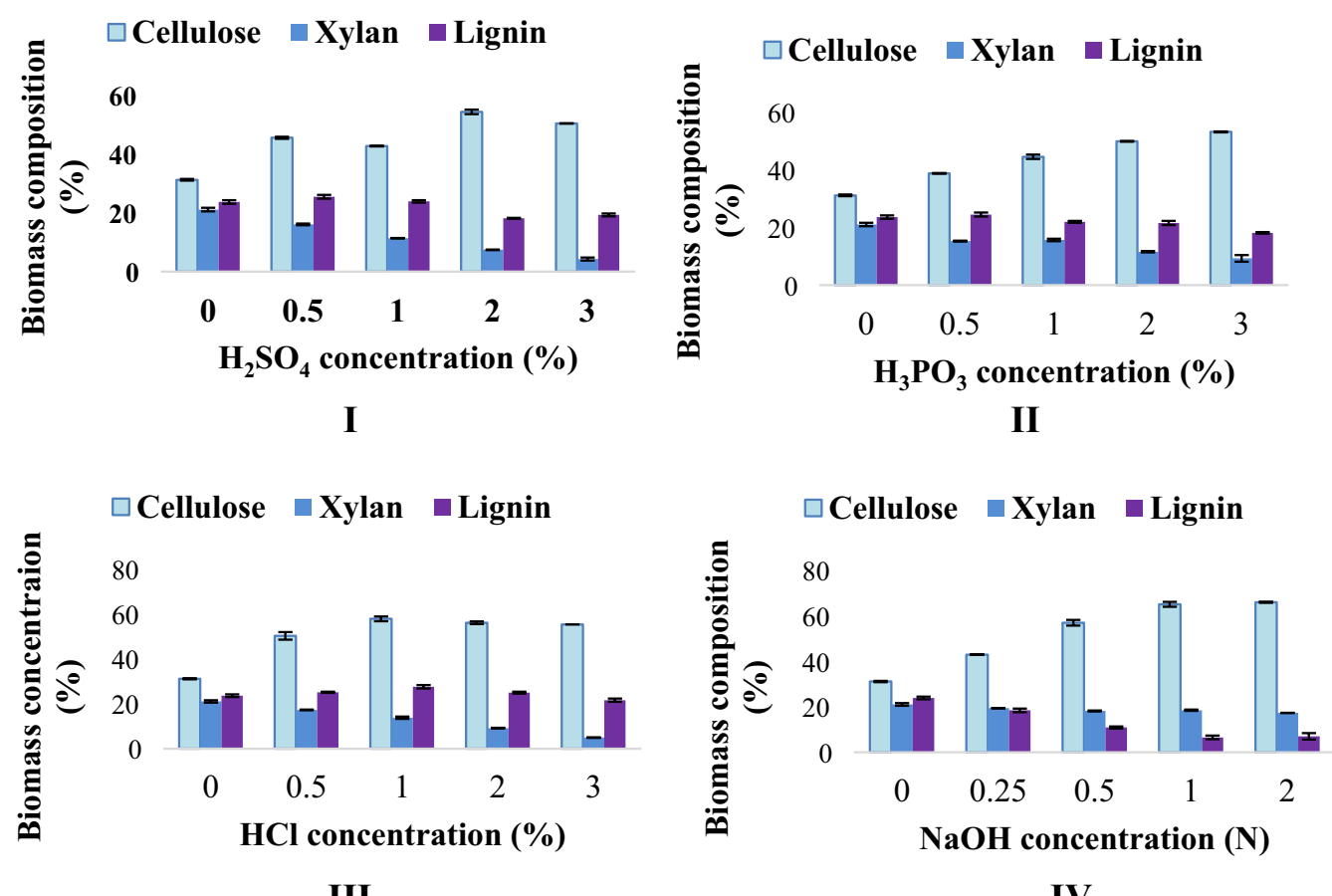

III

\section{IV}

Fig. 3 Analysis of sugarcane bagasse constituents resulted from different chemical pretreatments at various concentrations (I-IV) 

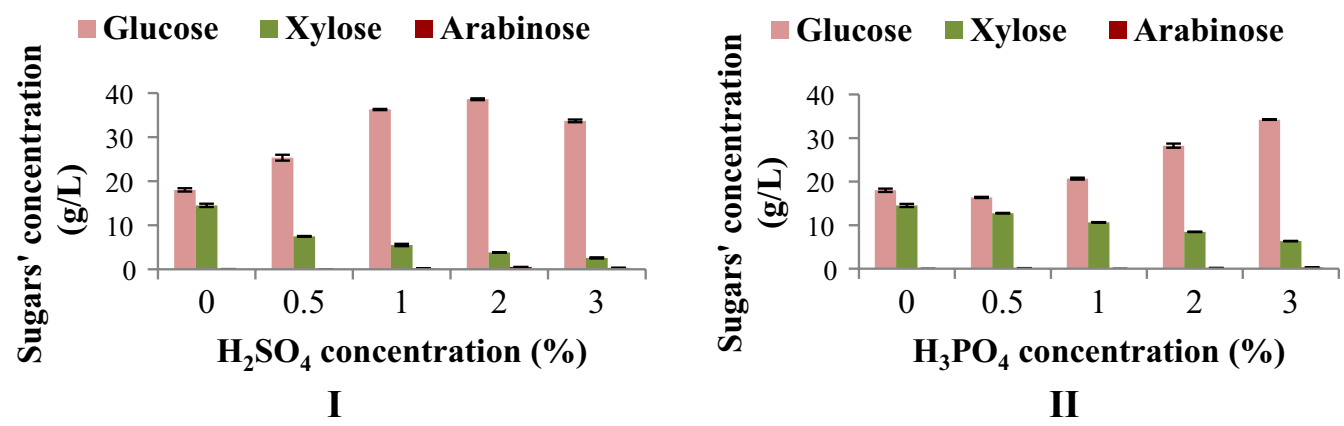

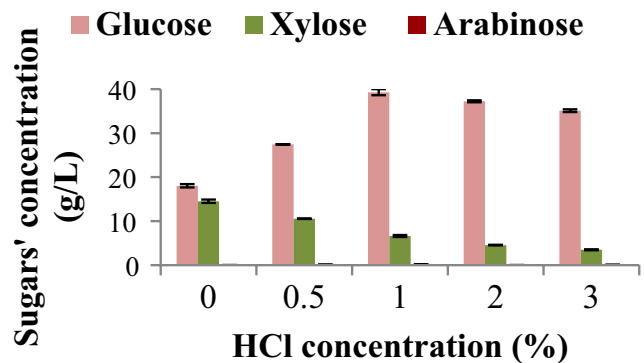

III

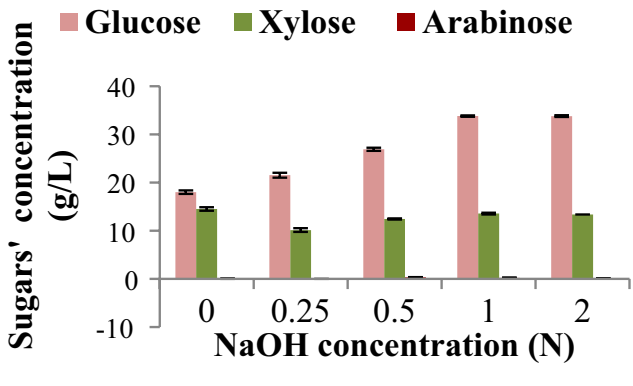

IV

Fig. 4 Sugars' concentrations after enzymatic hydrolysis following different pretreatment methods using SCB $100 \mathrm{~g} / \mathrm{L}$ (I-IV)

Table 1 Ethanol yield of Bacillus licheniformis KU886221 using differently pretreated SCB

\begin{tabular}{|c|c|c|c|c|}
\hline $\begin{array}{l}\text { Serial } \\
\text { no. }\end{array}$ & Pretreatment & $\begin{array}{l}\text { Incuba- } \\
\text { tion (h) }\end{array}$ & $\begin{array}{l}\text { Total sugars } \\
(\mathrm{g} / \mathrm{L})^{\mathrm{a}}\end{array}$ & Ethanol (g/L) \\
\hline \multirow[t]{4}{*}{1} & \multirow[t]{4}{*}{$2 \% \mathrm{H}_{2} \mathrm{SO}_{4}$} & 0 & $41.227^{b} \pm 0.430$ & $0^{i}$ \\
\hline & & 24 & $36.556^{\mathrm{cd}} \pm 0.675$ & $0.926^{g h} \pm 0.229$ \\
\hline & & 72 & $32.943^{\mathrm{efg}} \pm 1.009$ & $2.103^{\text {cde }} \pm 0.167$ \\
\hline & & 120 & $31.434^{\mathrm{fgh}} \pm 0.570$ & $2.61^{\mathrm{abc}} \pm 0.118$ \\
\hline \multirow[t]{4}{*}{2} & \multirow[t]{4}{*}{$3 \% \mathrm{H}_{3} \mathrm{PO}_{4}$} & 0 & $39.573^{\text {de }} \pm 0.718$ & $0^{i}$ \\
\hline & & 24 & $35.720^{g h} \pm 0.325$ & $1.126^{\mathrm{fgh}} \pm 0.117$ \\
\hline & & 72 & $31.277^{h i} \pm 0.657$ & $2.44^{b c d} \pm 0.092$ \\
\hline & & 120 & $29.997^{i} \pm 0.928$ & $2.863^{a b} \pm 0.154$ \\
\hline \multirow[t]{4}{*}{3} & \multirow[t]{4}{*}{$1 \% \mathrm{HCl}$} & 0 & $44.964^{a} \pm 0.527$ & $0^{i}$ \\
\hline & & 24 & $39.427^{b c} \pm 0.562$ & $1.155^{\mathrm{fgh}} \pm 0.159$ \\
\hline & & 72 & $34.533^{\mathrm{def}} \pm 0.595$ & $2.06 d^{e} \pm 0.097$ \\
\hline & & 120 & $32.317^{f g} \pm 0.202$ & $2.56^{\mathrm{bcd}} \pm 0.066$ \\
\hline \multirow[t]{4}{*}{4} & \multirow[t]{4}{*}{$1 \mathrm{~N} \mathrm{NaOH}$} & 0 & $45.919^{a} \pm 0.239$ & $0^{i}$ \\
\hline & & 24 & $41.371^{b} \pm 0.523$ & $1.24^{\mathrm{fgh}} \pm 0.244$ \\
\hline & & 72 & $35.687^{\text {de }} \pm 0.603$ & $2.793^{\mathrm{ab}} \pm 0.164$ \\
\hline & & 120 & $31.800^{f g} \pm 0.443$ & $3.313^{a} \pm 0.266$ \\
\hline \multirow[t]{4}{*}{5} & \multirow{4}{*}{$\begin{array}{l}\text { Control } \\
\text { (untreated) }\end{array}$} & 0 & $35.218^{\mathrm{de}} \pm 0.248$ & $0^{i}$ \\
\hline & & 24 & $31.053^{\text {gh }} \pm 0.335$ & $0.69^{h} \pm 0.039$ \\
\hline & & 72 & $26.943^{i} \pm 0.329$ & $1.553^{\mathrm{efg}} \pm 0.073$ \\
\hline & & 120 & $23.996^{j} \pm 0.305$ & $1.68^{\mathrm{ef}} \pm 0.037$ \\
\hline
\end{tabular}

a Glucose + xylose. Values signify mean \pm SE of triplicates. Values that do not share an alphabet are significantly different from each other. Multi-factor analysis of variance $(P<0.05)$
Optimization of enzymatic hydrolysis by central composite design

The optimum levels of Cellic Ctec 2 and Cellic Htec 2 Novozymes were obtained by solving the regression equation and analysis of the response surface contour plots. The global desirability function was also accomplished. The concentrations of Ctec and Htec Novozymes, ranging from 0.718 to $1.28 \mathrm{~g} / 100 \mathrm{~g}$ of alkaline pretreated SCB and 0.118 to $0.68 \mathrm{~g} / 100 \mathrm{~g}$ of alkaline pretreated SCB, respectively, were selected as independent variables (Table 3 ). The experimental design matrix is presented in Table 4 showing 11 experimental runs.

Analyzing the data from Tables 5 and 6, the model adequately adjusted to the experimental points, representing the confidence of the dependent variable analyzed. Considering the confidence level of $95 \%$, the model obtained was significant, since the determination coefficient $R^{2}$ value was equal to 0.94 and adjusted $R^{2}$ was equal to 0.84 . The lack of fit was insignificant (above 0.05) combined with the significant $F$ and $P$ values.

The response surface of the experimental design (Fig. 5) elucidates the effect of enzymatic hydrolysis on sugar liberation from sugarcane bagasse. The surfaces present the relation between dependent variables (Ctec and Htec enzymes) and independent factors (total sugars).

Global desirability value for optimized concentrations of dependent variables targeting for maximum 
Table 2 Ethanol yield of Bacillus licheniformis KU886221 using SCB hydrolysate

\begin{tabular}{|c|c|c|c|c|}
\hline Serial no. & Pretreatment & Incubation (h) & ${\text { Total sugars }(g / L)^{a}}^{a}$ & Ethanol (g/L) \\
\hline \multirow[t]{4}{*}{1} & \multirow[t]{4}{*}{$2 \% \mathrm{H}_{2} \mathrm{SO}_{4}$} & 0 & $41.952^{b c} \pm 0.417$ & $0^{9}$ \\
\hline & & 24 & $35.913^{\mathrm{ef}} \pm 0.676$ & $1.101^{f} \pm 0.124$ \\
\hline & & 72 & $27.811^{\mathrm{gh}} \pm 0.333$ & $3.491^{d} \pm 0.129$ \\
\hline & & 120 & $25.464^{\text {hi }} \pm 0.579$ & $4.294^{b c} \pm 0.315$ \\
\hline \multirow[t]{4}{*}{2} & \multirow[t]{4}{*}{$3 \% \mathrm{H}_{3} \mathrm{PO}_{3}$} & 0 & $38.405^{\text {de }} \pm 0.569$ & $0^{9}$ \\
\hline & & 24 & $33.823^{f} \pm 1.026$ & $1.593^{\mathrm{ef}} \pm 0.143$ \\
\hline & & 72 & $24.529^{i} \pm 0.580$ & $4.204^{b c} \pm 0.047$ \\
\hline & & 120 & $16.769^{k} \pm 0.299$ & $4.5413^{\mathrm{ab}} \pm 0.068$ \\
\hline \multirow[t]{4}{*}{3} & \multirow[t]{4}{*}{$1 \% \mathrm{HCl}$} & 0 & $44.919^{\mathrm{ab}} \pm 0.212$ & $0^{9}$ \\
\hline & & 24 & $41.214^{\mathrm{cd}} \pm 0.369$ & $1.165^{\mathrm{ef}} \pm 0.179$ \\
\hline & & 72 & $30.202^{g} \pm 0.431$ & $3.742^{\mathrm{cd}} \pm 0.080$ \\
\hline & & 120 & $29.170^{9} \pm 0.448$ & $4.282^{b c} \pm 0.053$ \\
\hline \multirow[t]{4}{*}{4} & \multirow[t]{4}{*}{$1 \mathrm{~N} \mathrm{NaOH}$} & 0 & $46.306^{a} \pm 0.465$ & 0 \\
\hline & & 24 & $39.345^{c d} \pm 0.126$ & $1.483^{\mathrm{ef}} \pm 0.097$ \\
\hline & & 72 & $28.981^{9} \pm 0.306$ & $3.955^{b c d} \pm 0.163$ \\
\hline & & 120 & $28.471^{g} \pm 0.575$ & $4.937^{\mathrm{a}} \pm 0.140$ \\
\hline \multirow[t]{4}{*}{5} & \multirow[t]{4}{*}{ Control (untreated) } & 0 & $33.902^{f} \pm 1.150$ & $0^{9}$ \\
\hline & & 24 & $29.061^{9} \pm 0.658$ & $0.420^{9} \pm 0.079$ \\
\hline & & 72 & $25.139^{h i} \pm 0.282$ & $1.681^{\mathrm{ef}} \pm 0.066$ \\
\hline & & 120 & $21.527^{j} \pm 0.545$ & $1.962^{e} \pm 0.090$ \\
\hline
\end{tabular}

a Glucose + xylose. Values signify mean \pm SE of triplicates. Values that do not share an alphabet are significantly different from each other. Multi-factor analysis of variance $(P<0.05)$

Table 3 Variables range in the central composite non-factorial experimental design

\begin{tabular}{llllll}
\hline Variable & \multicolumn{3}{l}{ Ranges and levels } & \\
\cline { 2 - 6 } & $\begin{array}{lllll}\text { Axial } \\
\mathbf{1 . 4 1}\end{array}$ & $\begin{array}{l}\text { Minimum } \\
\mathbf{- 1}\end{array}$ & Centre 0 & $\begin{array}{l}\text { Maximum } \\
\mathbf{1}\end{array}$ & $\begin{array}{l}\text { Axial } \\
\mathbf{1 . 4 1}\end{array}$ \\
\hline Ctec (g/100 g SCB) & 0.718 & 0.8 & 1 & 1.2 & 1.28 \\
Htec (g/100 g SCB) & 0.118 & 0.2 & 0.4 & 0.6 & 0.68 \\
\hline
\end{tabular}

production of response variable was 0.98, explaining the significance of the optimization by this method and justifying $98 \%$ of the maximum production of response variable (sugars). The optimal values of dependent variables (Ctec and Htec Novozymes) for sugar production from alkaline pretreated sugarcane bagasse were predicted from the desirability profile (see Additional file 1). It was proposed that by performing enzymatic hydrolysis

Table 4 Central composite non-factorial $\left(2^{2}\right)$ experimental design matrix showing selected variables and their response result as sugars production

\begin{tabular}{|c|c|c|c|c|c|}
\hline \multirow[t]{2}{*}{ Standard run } & \multicolumn{2}{|l|}{ Ctec (g/L) } & \multicolumn{2}{|l|}{ Htec (g/L) } & \multirow[t]{2}{*}{ Total sugars $(\mathrm{g} / \mathrm{L}$} \\
\hline & $\mathrm{X}_{1} \mathrm{~g} / 100 \mathrm{~g} \mathrm{SCB}$ & $\mathrm{X}_{1}$ coded value & $X_{2} g / 100 \mathrm{~g} \mathrm{SCB}$ & $X_{2}$ coded value & \\
\hline 1 & 0.8 & -1 & 0.2 & -1 & 31.07 \\
\hline 2 & 0.8 & -1 & 0.6 & 1 & 40.157 \\
\hline 3 & 1.2 & 1 & 0.2 & -1 & 39.8668 \\
\hline 4 & 1.2 & 1 & 0.6 & 1 & 38.941 \\
\hline 5 & 0.718 & -1.41 & 0.4 & 0 & 34.458 \\
\hline 6 & 1.28 & 1.41 & 0.4 & 0 & 41.109 \\
\hline 7 & 1 & 0 & 0.118 & -1.41 & 39.122 \\
\hline 8 & 1 & 0 & 0.68 & 1.41 & 46.359 \\
\hline $9(\mathrm{C})$ & 1 & 0 & 0.4 & 0 & 47.757 \\
\hline $10(\mathrm{C})$ & 1 & 0 & 0.4 & 0 & 48.873 \\
\hline $11(\mathrm{C})$ & 1 & 0 & 0.4 & 0 & 48.221 \\
\hline
\end{tabular}


Table 5 Statistics for the regression of the optimization model for enzymatic hydrolysis using $\mathrm{Ctec}$ and Htec Novozymes for sugars liberation

\begin{tabular}{lrrrr}
\hline & Regression & Standard error & Student's $\boldsymbol{t}$ & $\boldsymbol{P}$ \\
\hline Mean/interc. & -137.665 & 9.27795 & -14.8378 & 0.004511 \\
$\mathrm{X}_{1}(\mathrm{Ctec})(\mathrm{L})$ & 302.033 & 16.85682 & 17.9176 & 0.003100 \\
$\mathrm{X}_{1}^{2}(\mathrm{Ctec})(\mathrm{Q})$ & -133.247 & 8.18171 & -16.2860 & 0.003749 \\
$\mathrm{X}_{2}(\mathrm{Htec})(\mathrm{g} / \mathrm{L})$ & 130.403 & 11.72338 & 11.1234 & 0.007985 \\
$(\mathrm{~L})$ & & & & \\
$\mathrm{X}_{2}^{2}(\mathrm{Htec})(\mathrm{Q})$ & -70.464 & 8.18171 & -8.6124 & 0.013215 \\
$1 \mathrm{~L}$ by $2 \mathrm{~L}$ & -62.580 & 9.63643 & -6.4941 & 0.022900 \\
\hline
\end{tabular}

with $1.024 \mathrm{~g}$ Ctec $+0.468 \mathrm{~g}$ Htec/100 g of alkaline pretreated SCB, $47.503 \mathrm{~g}$ total sugars should be released. The validation experiments were conducted in triplicates. The experimental value of sugars obtained was $46.69 \mathrm{~g} / 100 \mathrm{~g}$ SCB with standard deviation of 0.675 that was within the confidence limits -95 and $+95 \%$, showing that these experimental findings were in full agreement with the model prediction (Table 7).

\section{Experimental design for optimization of fermentation using Taguchi orthogonal array}

Taguchi OA experimental design was incorporated for optimization of ethanol fermentation parameters using B. licheniformis KU886221. The three levels of six fermentation factors affecting the ethanol fermentation are described in Table 8, whereas the 27 runs Taguchi OA experimental design along with the results are shown in Table 9. The results show that the most suitable factors for ethanol fermentation are SCBH derived from $100 \mathrm{~g} / \mathrm{L}$ alkaline pretreated SCB, $20 \mathrm{~g} / \mathrm{L} \mathrm{CSL}, 1 \mathrm{~g} / \mathrm{L}$ sodium chloride $(\mathrm{NaCl}), 45{ }^{\circ} \mathrm{C}$ incubation temperature, incubation $\mathrm{pH}$ 9, and 5 days of incubation time. 3-D surface model graph of Taguchi OA experimental design shows the optimized levels of fermentation factors influencing ethanol production (Fig. 6).

Results of the 27 runs for the experimental design executed revealed that the maximum production of ethanol was expected to be $7.79 \mathrm{~g} / \mathrm{L}$ with standard deviation 0.446 under the optimized conditions of fermentation factors. However, under these selected fermentation conditions, the ethanol production appeared $7.612 \mathrm{~g} / \mathrm{L}$ with standard deviation of 0.178 (while performing experiment in triplicates). Since the variance between the predicted and actual production was $2.28 \%$, the result was considered as acceptable.

Analysis of variance (ANOVA) of the experimental design's results revealed that changing of incubation temperature and $\mathrm{pH}$ are the most important factors affecting ethanol fermentation (Table 10). Considering the confidence level of $99 \%$, the model obtained was significant, since the coefficient $R$-square $\left(R^{2}\right)$ value was equal to 0.96 and adjusted $R^{2}$ was equal to 0.855 . The Model $F$ value of 8.69 implies that the model is significant. There is only a $0.65 \%$ chance that a "Model $F$ value" of this large could occur due to noise.

\section{Bench-scale ethanol fermentation employing $B$. licheniformis KU886221 \\ Fermentation in bioreactor}

In batch fermentation of B. licheniformis KU886221 in stirred-tank bioreactor for ethanol production, maximum productivity of $0.205 \mathrm{~g} / \mathrm{L} \mathrm{h}$ was obtained at $36 \mathrm{~h}$ of fermentation, whereas overall yield of batch fermentation was $0.245 \mathrm{~g}$ of ethanol/g of sugars (glucose + xylose) consumed which corresponds to $0.909 \mathrm{~mol}$ of ethanol $/ \mathrm{mol}$ of sugars consumed (Fig. 7). The percentage reduction of substrate (PRS) was 98.4 which is significant amount of substrate consumption into product. In terms of biomass, $0.114 \mathrm{~g}$ ethanol $/ \mathrm{g}$ of alkaline pretreated SCB was produced. Cell density was noted by measuring the optical density of the cell suspension during batch fermentation. The bacterial growth ranged from 0.168 to 1.86 O.D. at 12 and $60 \mathrm{~h}$ postinoculations, respectively.

Figure 8 presents the results of fermentation kinetics of batch fermentation in bioreactor at the end of $84 \mathrm{~h}$ of fermentation. It shows that along with ethanol, some

Table 6 Analysis of variance (ANOVA) for enzymatic hydrolysis using Ctec and Htec Novozymes for sugars' yield

\begin{tabular}{lccrrr}
\hline & Sum of squares & Degree of freedom & Mean square & $\boldsymbol{F}$ & $\boldsymbol{P}$ value \\
\hline Ctec (L) & 35.0942 & 1 & 35.0942 & 59.0503 & 0.016516 \\
Ctec (Q) & 157.6309 & 1 & 157.6309 & 265.2338 & 0.003749 \\
Htec (L) & 41.6941 & 1 & 41.6941 & 70.1556 & 0.013956 \\
Htec (Q) & 44.0817 & 1 & 44.0817 & 74.1731 & 0.013215 \\
L by 2L & 25.0640 & 1 & 25.0640 & 42.1734 \\
Lack of fit & 14.9972 & 3 & 4.9991 & 8.4116 & 0.022900 \\
Pure error & 1.1886 & 2 & 0.5943 & 0.108106 \\
Total SS & 287.2233 & 10 & & \\
\hline
\end{tabular}


Fitted S urface; Response Variable: S ugar (g/L)

2 factors, 1 Blocks, 11 Runs; MS Pure Error=0.594

DV: S ugar (g/L)

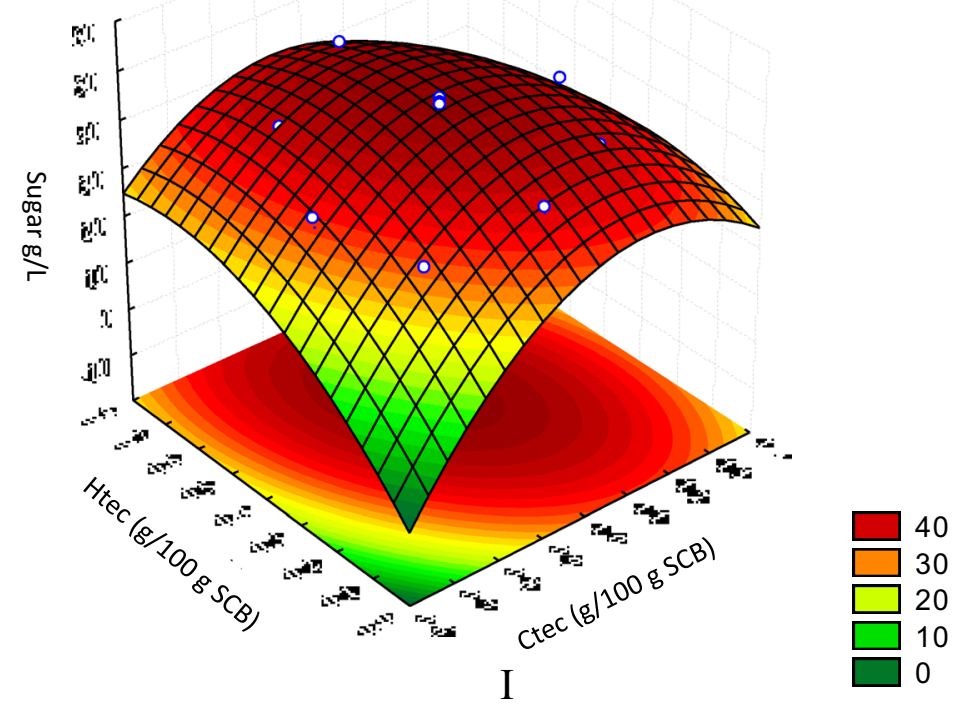

Fitted Surface; Variable: Sugar (g/L)

2 factors, 1 Blocks, 11 Runs; MS Pure Error=.5943093

DV: Sugar $(g / L)$

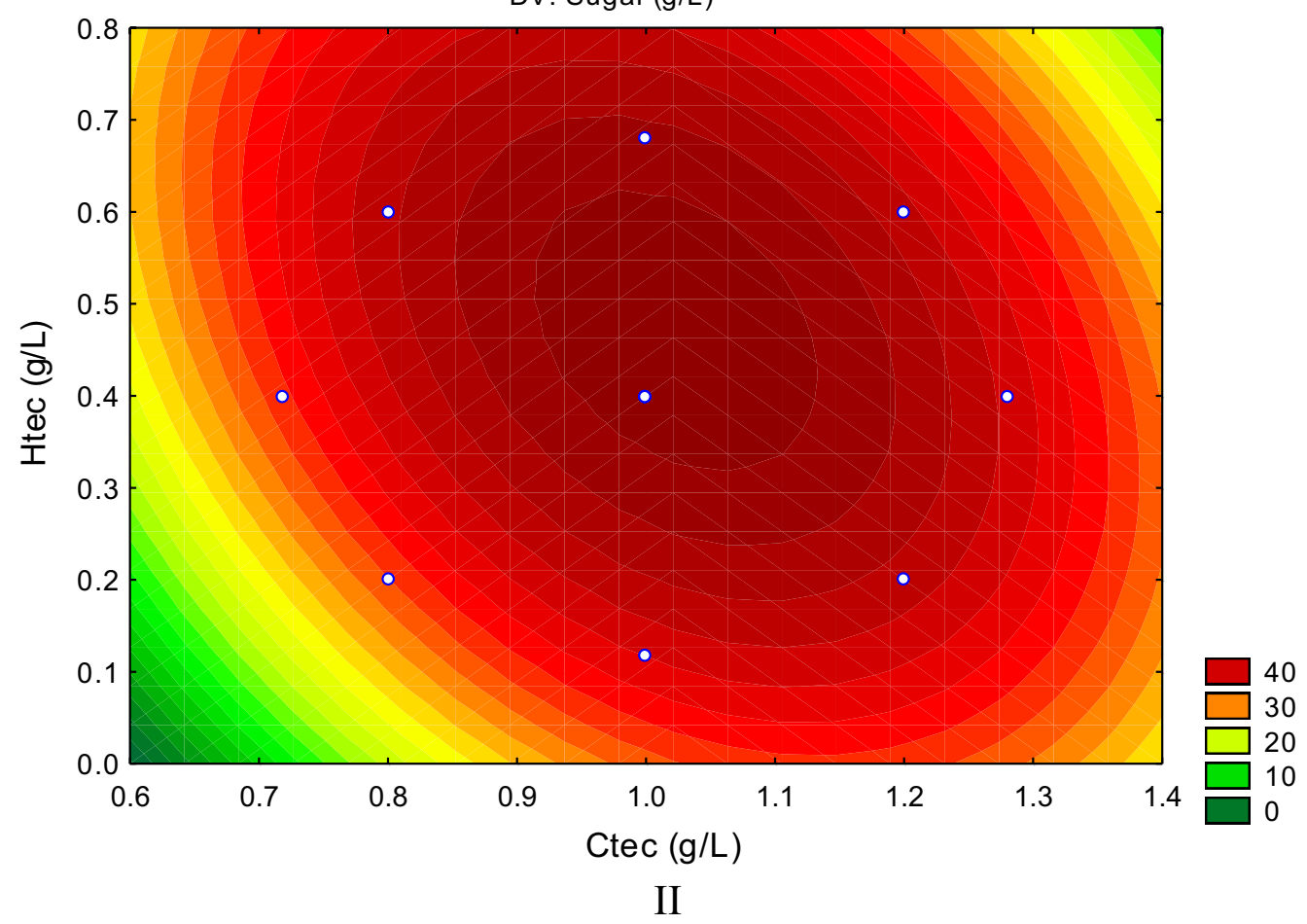

Fig. 5 Response surface and contour plots indicating the effect of Ctec and Htec Novozymes on hydrolysis of alkaline pretreated sugarcane bagasse (I, II) 
Table 7 Validation experiment analysis for hydrolysis of alkaline pretreated SCB for obtaining maximum quantity of simple sugars

\begin{tabular}{|c|c|c|c|c|c|}
\hline \multirow[t]{2}{*}{ Factor } & \multirow[t]{2}{*}{ Desirability } & \multicolumn{2}{|c|}{ Limit \% } & \multirow[t]{2}{*}{ Predicted value $(\mathrm{g} / \mathrm{L})$} & \multirow{2}{*}{$\begin{array}{l}\text { Experimental } \\
\text { value }(\mathrm{g} / \mathrm{L})\end{array}$} \\
\hline & & -95 & +95 & & \\
\hline Sugar (g/L) & 0.984759 & 45.66 & 49.34526 & 47.503 & $46.69 \pm 0.675$ \\
\hline
\end{tabular}

Table 8 Selected three levels of fermentation factors for ethanol production from Bacillus licheniformis KU886221 using Taguchi OA experimental design

\begin{tabular}{|c|c|c|c|c|c|c|}
\hline Serial no. & Factor & Name & Units & Low level & Level & High level \\
\hline 1 & A & $\mathrm{SCBH}$ & $g / L$ & 90 & 100 & 110 \\
\hline 2 & B & CSL & $\mathrm{g} / \mathrm{L}$ & 10 & 20 & 30 \\
\hline 3 & C & $\mathrm{NaCl}$ & $g / L$ & 1 & 2 & 3 \\
\hline 4 & D & Temp. & C & 40 & 45 & 50 \\
\hline 5 & E & $\mathrm{pH}$ & $0-14$ & 8 & 9 & 10 \\
\hline 6 & $\mathrm{~F}$ & Incu. time & Day & 1 & 2 & 3 \\
\hline
\end{tabular}

Table 9 Taguchi experimental design for optimization of fermentation parameters for ethanol production from Bacillus licheniformis KU886221

\begin{tabular}{|c|c|c|c|c|c|c|c|}
\hline Run & $\mathrm{SCBH}(g / L)$ & $\operatorname{CSL}(g / L)$ & $\mathrm{NaCl}(\mathrm{g} / \mathrm{L})$ & Temp $\left({ }^{\circ} \mathrm{C}\right)$ & $\mathrm{pH}$ & Incubation (days) & Ethanol (g/L) \\
\hline 1 & 100 & 10 & 3 & 45 & 10 & 1 & 0.547 \\
\hline 2 & 100 & 20 & 1 & 45 & 8 & 2 & 2.938 \\
\hline 3 & 90 & 30 & 3 & 40 & 10 & 3 & 0.661 \\
\hline 4 & 90 & 30 & 3 & 45 & 8 & 1 & 1.650 \\
\hline 5 & 90 & 10 & 1 & 50 & 10 & 3 & 0.815 \\
\hline 6 & 100 & 10 & 3 & 40 & 9 & 3 & 3.214 \\
\hline 7 & 90 & 20 & 2 & 45 & 10 & 3 & 0.555 \\
\hline 8 & 100 & 10 & 3 & 50 & 8 & 2 & 1.106 \\
\hline 9 & 90 & 10 & 1 & 45 & 9 & 2 & 3.953 \\
\hline 10 & 100 & 30 & 2 & 40 & 8 & 2 & 2.146 \\
\hline 11 & 100 & 30 & 2 & 45 & 9 & 3 & 4.808 \\
\hline 12 & 90 & 30 & 3 & 50 & 9 & 2 & 0.471 \\
\hline 13 & 110 & 10 & 2 & 45 & 8 & 3 & 4.225 \\
\hline 14 & 110 & 20 & 3 & 45 & 9 & 1 & 2.678 \\
\hline 15 & 110 & 10 & 2 & 50 & 9 & 1 & 0.204 \\
\hline 16 & 110 & 10 & 2 & 40 & 10 & 2 & 0.362 \\
\hline 17 & 90 & 20 & 2 & 40 & 9 & 2 & 3.143 \\
\hline 18 & 100 & 20 & 1 & 40 & 10 & 1 & 0.840 \\
\hline 19 & 110 & 30 & 1 & 45 & 10 & 2 & 1.779 \\
\hline 20 & 90 & 20 & 2 & 50 & 8 & 1 & 0.086 \\
\hline 21 & 110 & 20 & 3 & 50 & 10 & 2 & 0.107 \\
\hline 22 & 110 & 30 & 1 & 50 & 8 & 3 & 0.434 \\
\hline 23 & 90 & 10 & 1 & 40 & 8 & 1 & 1.025 \\
\hline 24 & 100 & 20 & 1 & 50 & 9 & 3 & 0.854 \\
\hline 25 & 110 & 20 & 3 & 40 & 8 & 3 & 3.596 \\
\hline 26 & 100 & 30 & 2 & 50 & 10 & 1 & 0.106 \\
\hline 27 & 110 & 30 & 1 & 40 & 9 & 1 & 1.359 \\
\hline
\end{tabular}



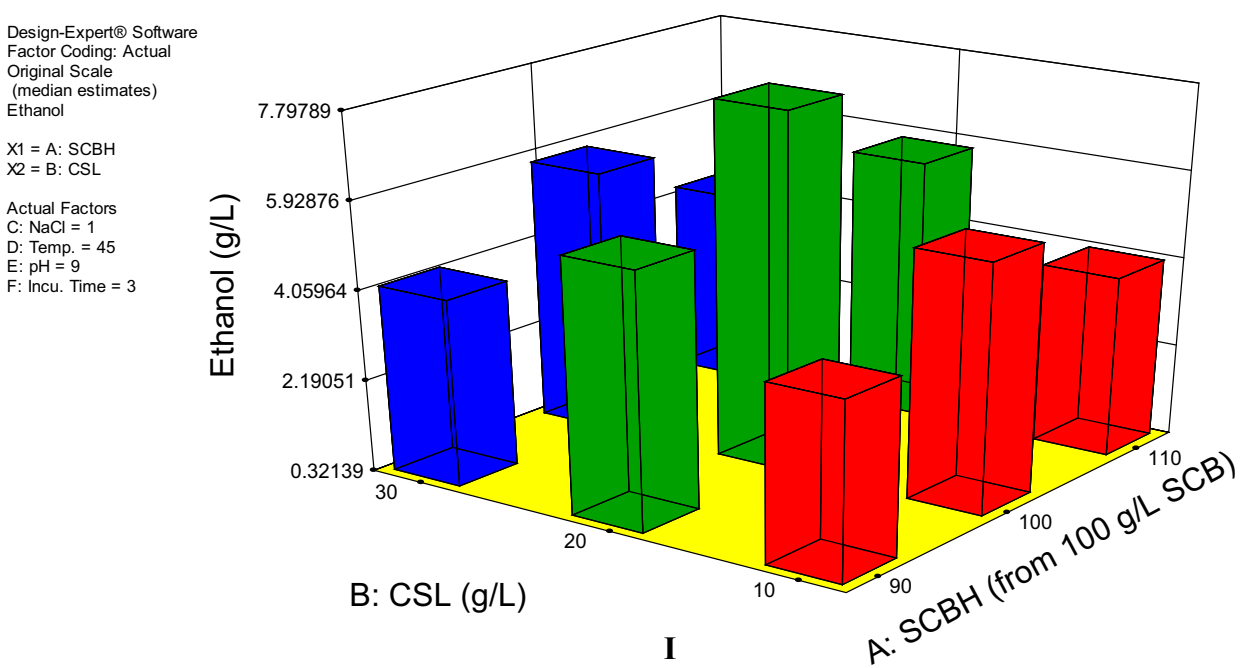

Design-Expert $₫$ Software Factor Coding: Actual Original Scale (median estimates) Ethanol

$\mathrm{X} 1=\mathrm{C}: \mathrm{NaCl}$ $\mathrm{X}_{2}=\mathrm{D}:$ Temp.

Actual Factors A: $\mathrm{SCBH}=90$

B: $\mathrm{CSL}=10$

$\mathrm{E}: \mathrm{pH}=9$

$\mathrm{F}$ : Incu. Time $=3$

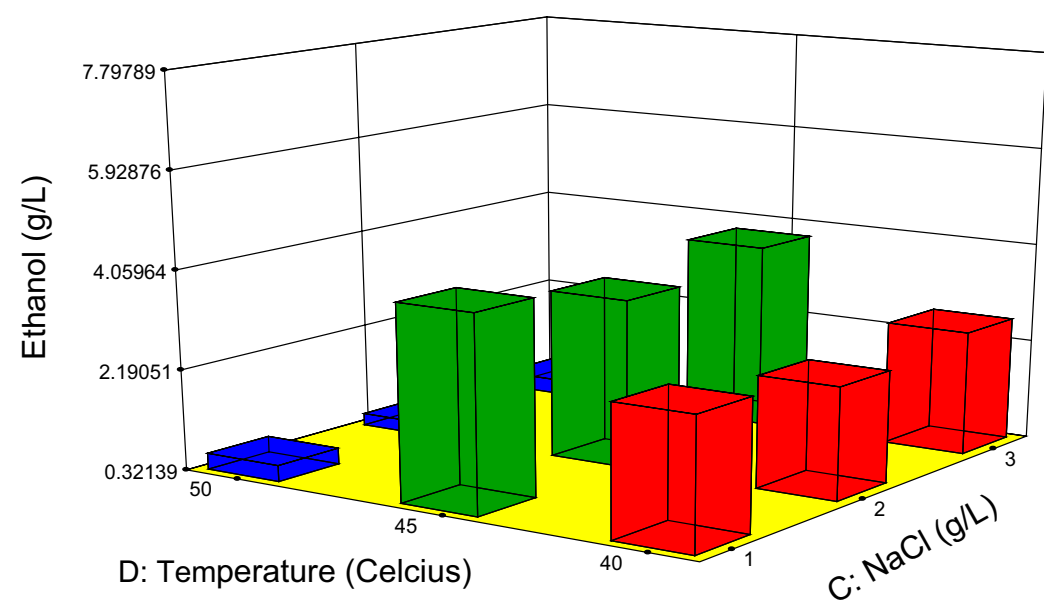

II

Design-Expert@ Software

Factor Coding: Actual

Original Scale

(median estimates)

- Design points above predicted value

$\mathrm{X} 1=\mathrm{E}: \mathrm{pH}$

$\mathrm{X}_{2}=\mathrm{F}$ : Incu. Time

Actual Factors

A: $\mathrm{SCBH}=100$

B: $\mathrm{CSL}=20$

C: $\mathrm{NaCl}=1$

D: Temp. $=45$

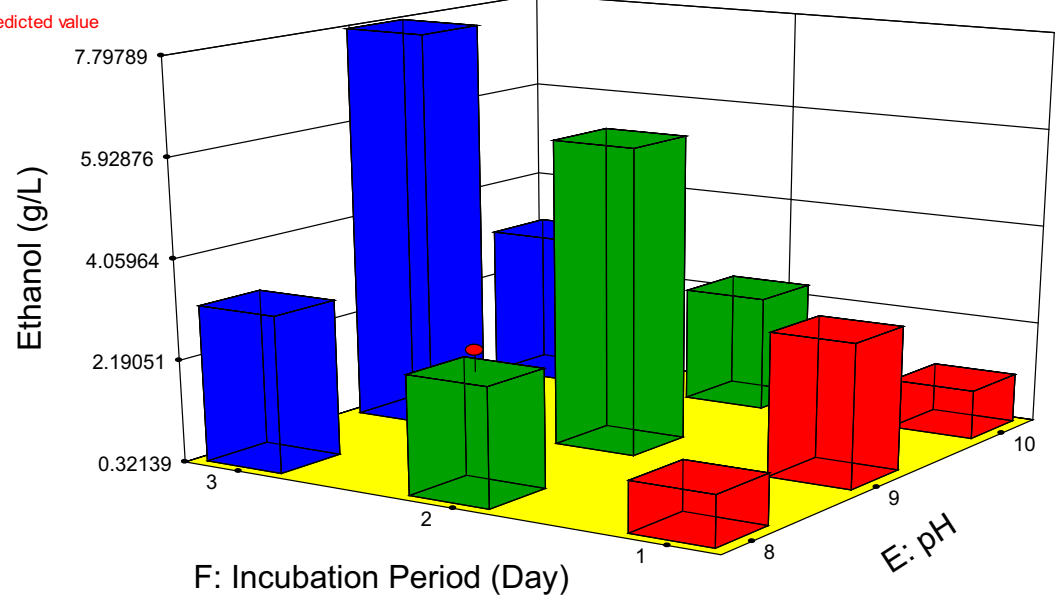

III

Fig. 6 3-D surface model graph of Taguchi OA experimental design showing optimized levels of fermentation factors influencing ethanol production. I SCBH and CSL were set as variables; II incubation temperature and NaCl were set as variables; III incubation pH and incubation period were set as variables 
Table 10 Results of analysis of variance (ANOVA) of the Taguchi OA experimental design

\begin{tabular}{|c|c|c|c|c|c|}
\hline Source & Sum of squares & Degree of freedom & Mean square & $F$ value & $\begin{array}{l}P \text { value } \\
\text { Prob }>F\end{array}$ \\
\hline Model & 34.76 & 20 & 1.74 & 8.69 & 0.0065 \\
\hline $\mathrm{A}-\mathrm{SCBH}$ & 0.55 & 2 & 0.28 & 1.39 & 0.3197 \\
\hline B-CSL & 0.19 & 2 & 0.095 & 0.48 & 0.6432 \\
\hline $\mathrm{C}-\mathrm{NaCl}$ & 1.39 & 2 & 0.69 & 3.46 & 0.0999 \\
\hline D-temp. & 17.42 & 2 & 8.71 & 43.57 & 0.0003 \\
\hline $\mathrm{E}-\mathrm{pH}$ & 7.5 & 2 & 3.75 & 18.75 & 0.0026 \\
\hline F-incubation time & 4.32 & 2 & 2.16 & 10.8 & 0.0103 \\
\hline BE & 0.74 & 4 & 0.19 & 0.93 & 0.506 \\
\hline CE & 2.65 & 4 & 0.66 & 3.31 & 0.0929 \\
\hline Residual & 1.2 & 6 & 0.2 & & \\
\hline Cor total & 35.96 & 26 & & & \\
\hline
\end{tabular}

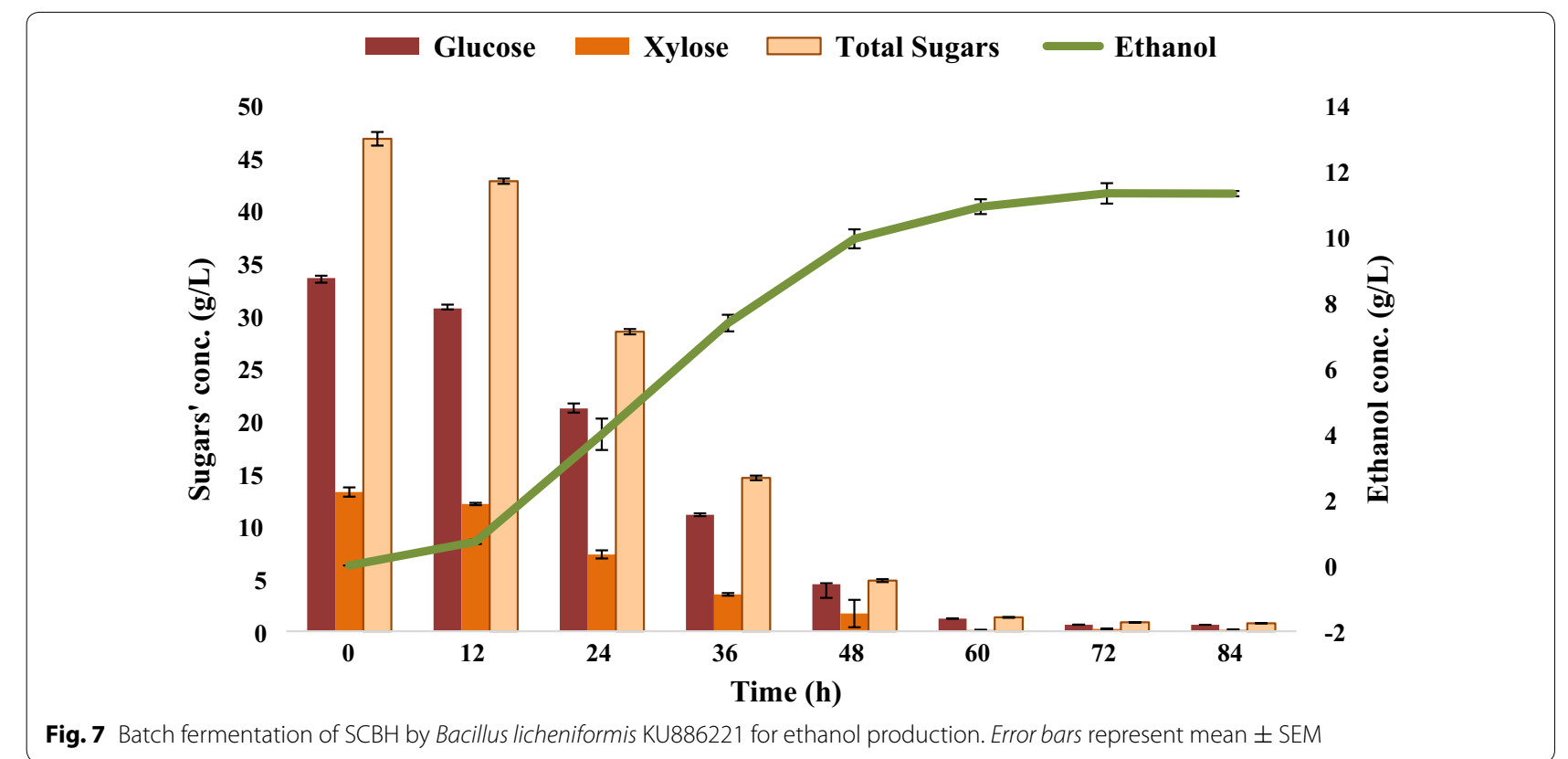

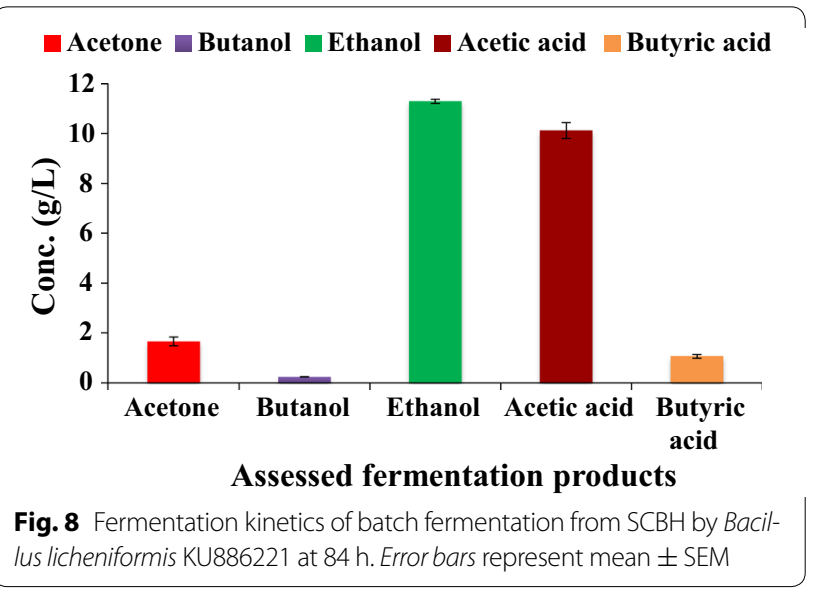

acetone and butanol were also produced, whereas lesser amount of acetic acid was also produced from ethanol due to which $\mathrm{pH}$ of the medium decreased.

Fed-batch fermentation The results of fed-batch fermentation showed that when substrate addition was made, the overall substrate consumption increased showing that the fermentative microbes consumed more substrate and produced more product (Fig. 9). However, after attaining a certain level of ethanol or toxic metabolites, the fermentative microbes stopped producing ethanol despite the presence of substrate in the fermentation medium. The ethanol yield was found to be $0.264 \mathrm{~g} / \mathrm{g}$ of sugars consumed which corresponded to $0.973 \mathrm{~mol}$ of ethanol/ 


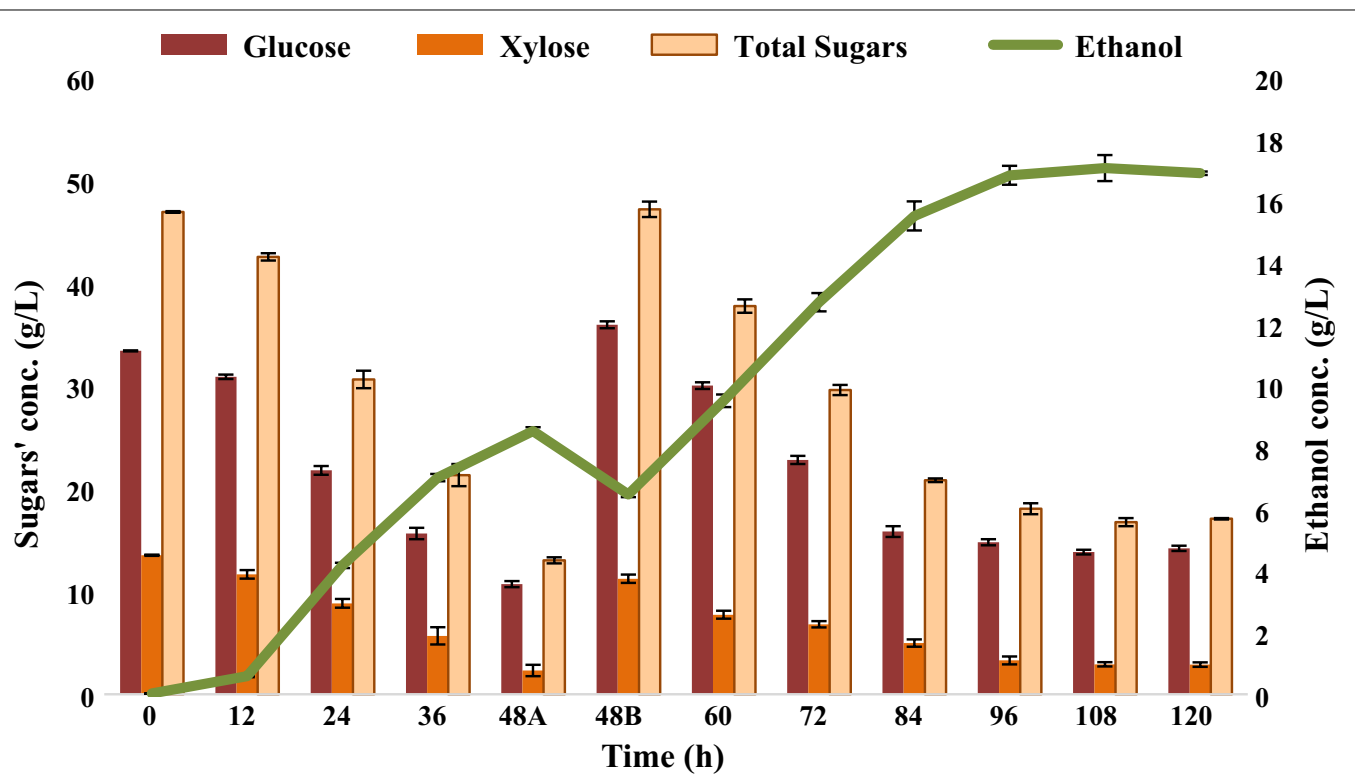

Fig. 9 Fed-batch fermentation of SCBH by Bacillus licheniformis KU886221 for ethanol production. 48A-before addition of second feed and 48B: following second feed $5 \times(200 \mathrm{~mL})$. Error bars represent mean \pm SEM

mol of sugars consumed. In terms of biomass, $0.123 \mathrm{~g}$ ethanol/g of alkaline pretreated SCB was produced. The bacterial growth ranged from 0.164 to 1.925 O.D., at $12-$ and 96-h postinoculations, respectively.

Immobilized-cell fermentation using fibrous-bed bioreactor (FBB) The results of fed-batch fermentation involving FBB (Fig. 10) indicate that PRS was increased from 78.94 to 85.031 due to FBB attachment for fed-batch fermentation setup. The ethanol yield was $0.279 \mathrm{~g} / \mathrm{g}$ of sugars consumed which corresponds to $1.07 \mathrm{~mol}$ of ethanol/ mol of sugars consumed. In terms of biomass, $0.131 \mathrm{~g}$ of ethanol/g of alkaline pretreated SCB was produced. The bacterial growth ranged from 0.432 to 1.353 O.D. at 12and 72-h postinoculations, respectively. The fermentation kinetics of the immobilized-cell fermentation using FBB was studied at the end of fermentation (Fig. 11).

At the end of fed-batch fermentation involving FBB, the downstream product recovery was done though gas stripping. After $3 \mathrm{~h}$ of gas stripping, a total of $158 \mathrm{~mL}$ of condensate containing $56.88 \mathrm{~g} / \mathrm{L}$ ethanol, $15.18 \mathrm{~g} / \mathrm{L}$ acetone, and $20.02 \mathrm{~g} / \mathrm{L}$ butanol were obtained.

Effect of ethanol removal on fermentation Next experiment elucidates the effect of partial ethanol removal during fed-batch fermentation involving FBB on the ethanol fermentation (Fig. 12). The gas stripping was done at $60 \mathrm{~h}$ of fermentation when the ethanol titer was above $10 \mathrm{~g} / \mathrm{L}$. Significant increase in ethanol production from 19.389 to $22.97 \mathrm{~g} / \mathrm{L}$ was observed by removing the ethanol during fermentation which corresponded to 1.1407 mol of ethanol per mole of sugars consumed. In terms of biomass, $0.135 \mathrm{~g}$ of ethanol/g of alkaline pretreated SCB was produced. The bacterial growth ranged from 0.236 to 1.788 O.D. at 12- and 96-h postinoculation, respectively. In addition, significantly greater amount of condensate $(260 \mathrm{~mL})$ was obtained as a result of $6 \mathrm{~h}$ of gas stripping containing $58.1 \mathrm{~g} / \mathrm{L}$ ethanol, $16.9 \mathrm{~g} / \mathrm{L}$ acetone, and $21.6 \mathrm{~g} / \mathrm{L}$ butanol.

Bioethanol production under non-aseptic conditions The fed-batch fermentation involving FBB was studied under non-aseptic fermentation for ethanol production (Figs. 13, 14). In terms of biomass, $0.089 \mathrm{~g}$ of ethanol $/ \mathrm{g}$ of alkaline pretreated SCB was produced. The bacterial growth ranged from 0.218 to 2.459 O.D. at 12 and $96 \mathrm{~h}$ post inoculations, respectively. Overall yield decreased compared to aseptic fermentation conditions from $0.279 \mathrm{~g}$ of ethanol $/ \mathrm{g}$ of substrate to 0.192 which corresponds to $0.5703 \mathrm{~mol}$ ethanol per mole of sugar consumed. At the end of nonaseptic fermentations by $B$. licheniformis KU886221, low quantity of condensate $(120 \mathrm{~mL})$ was obtained following gas stripping containing $51.12 \mathrm{~g} / \mathrm{L}$ ethanol, $6.79 \mathrm{~g} / \mathrm{L}$ acetone, and $32.08 \mathrm{~g} / \mathrm{L}$ butanol.

\section{Discussion}

Principal aim of this study was to extract the energy from renewable waste sugarcane bagasse under nonaseptic extreme conditions in the form of bioethanol. For this purpose, alkali-thermophilic ethanologens were isolated from the soil sampled from the vicinity of 


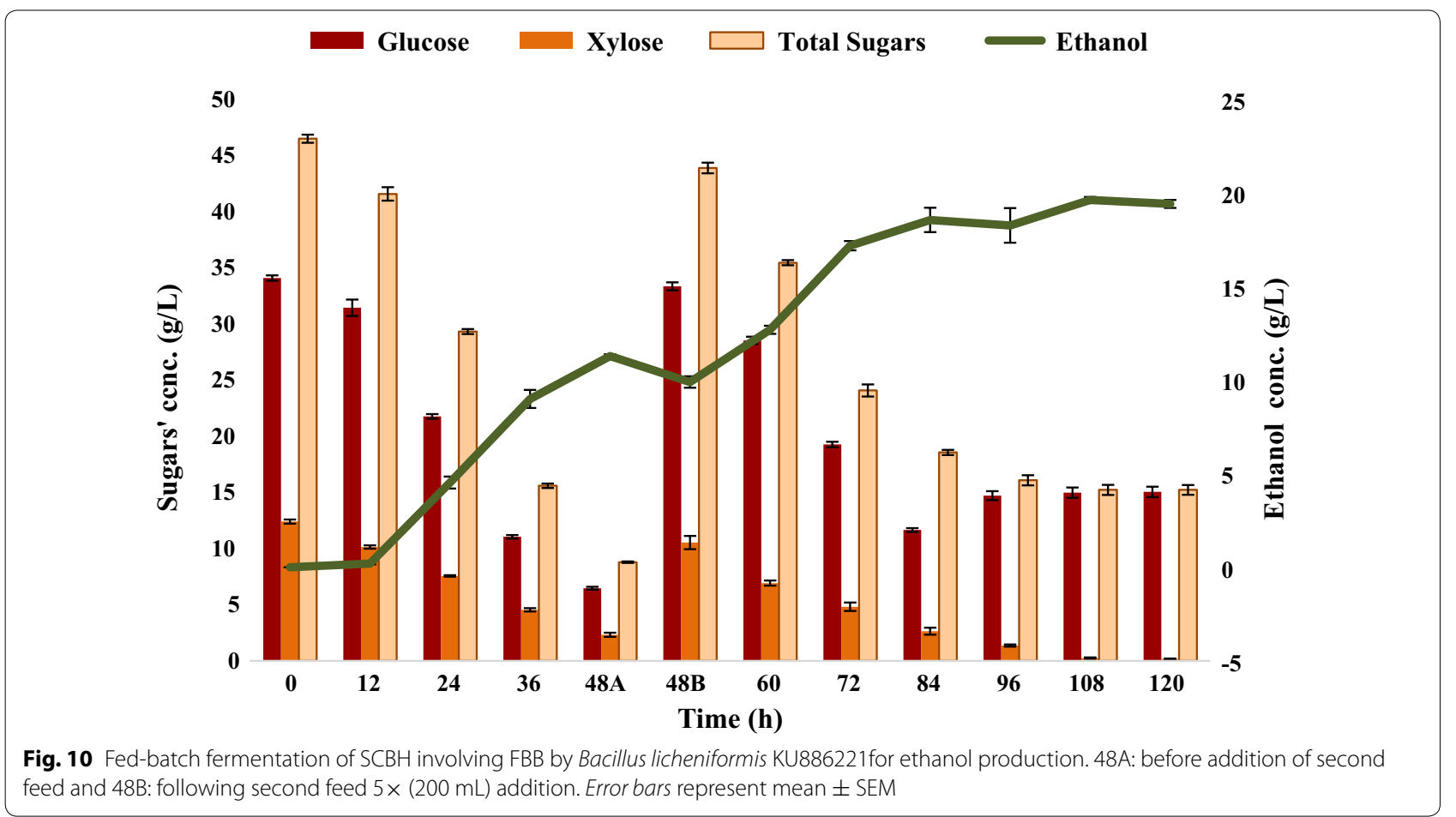

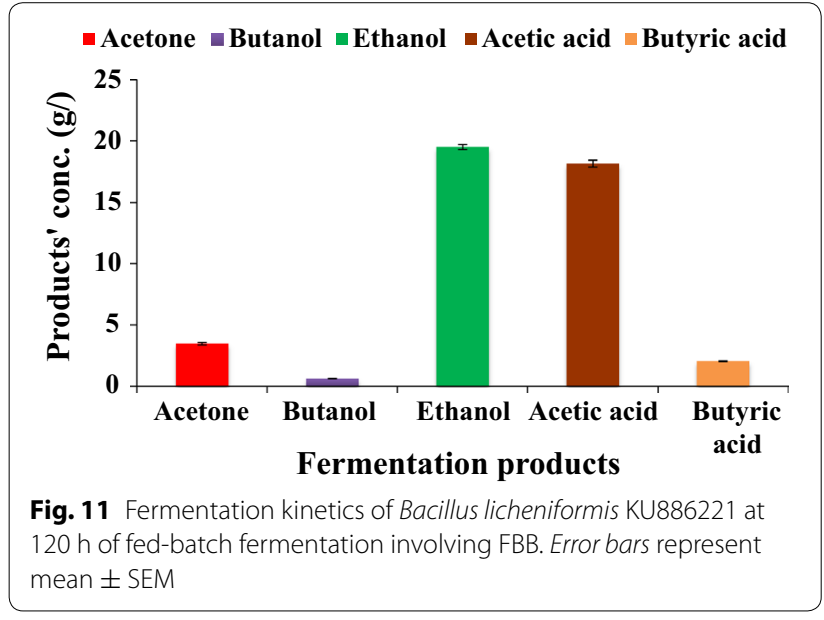

hot water effluent near Balkasar oil refinery, Chakwal, Pakistan. The mud temperature was $50-55{ }^{\circ} \mathrm{C}$ with $\mathrm{pH}$ ranging $9-10$ at the sampling time. Such habitats are favorable conditions for isolation of alkali-thermophiles [26]. Further valuation of cellulolytic/ethanologenic potential of the isolates was done by replacing glucose with sugarcane bagasse as substrate in the fermentation medium. On the basis of higher ethanol production, isolate ML-07 was selected, pure-cultured, and identified through 16S rRNA gene sequencing, and was recognized as a cellulolytic and mild alkali-thermophilic strain of $B$. licheniformis. Consequently, it was allotted the accession no. KU886221. It was previously reported that some strains of $B$. licheniformis were found to produce ethanol in fermentation medium [27].

As mentioned before, SCB was selected as substrate for ethanol fermentation. Composition of sugarcane bagasse was $31.168 \%$ cellulose, $21.048 \%$ xylan, and $23.633 \%$ lignin. Many thermophilic bacteria capable of utilizing hexoses/pentoses from cellulose/hemicellulose, respectively, directly/indirectly are considered promising for ethanol fermentation [16, 28-30]. For that reason, it can be speculated that both cellulose and hemicellulose are valuable carbon substrates for thermophilic ethanol fermentation.

Cellulose is generally recalcitrant to hydrolysis; therefore, ethanol production from lignocellulosic biomass requires separation of its fractions through pretreatment methods [31]. The chemicals used in pretreatment expose the crystalline cellulose and enhance its porosity by breaking down lignin protection around it, which, in turn, facilitates polysaccharide hydrolysis [32, 33]. For this purpose, optimum pretreatment concentrations of $\mathrm{H}_{2} \mathrm{SO}_{4}, \mathrm{H}_{3} \mathrm{PO}_{4}, \mathrm{HCl}$, and $\mathrm{NaOH}$ for $\mathrm{SCB}$ hydrolysis were explored. The outcomes indicated that the alkaline pretreatment with $1 \mathrm{~N}$ sodium hydroxide of SCB significantly reduced lignin contents and produced cumulatively greater sugar contents (glucose and xylose) after enzymatic hydrolysis as presented in Additional file 2 . This is analogous to the findings of previously reported 

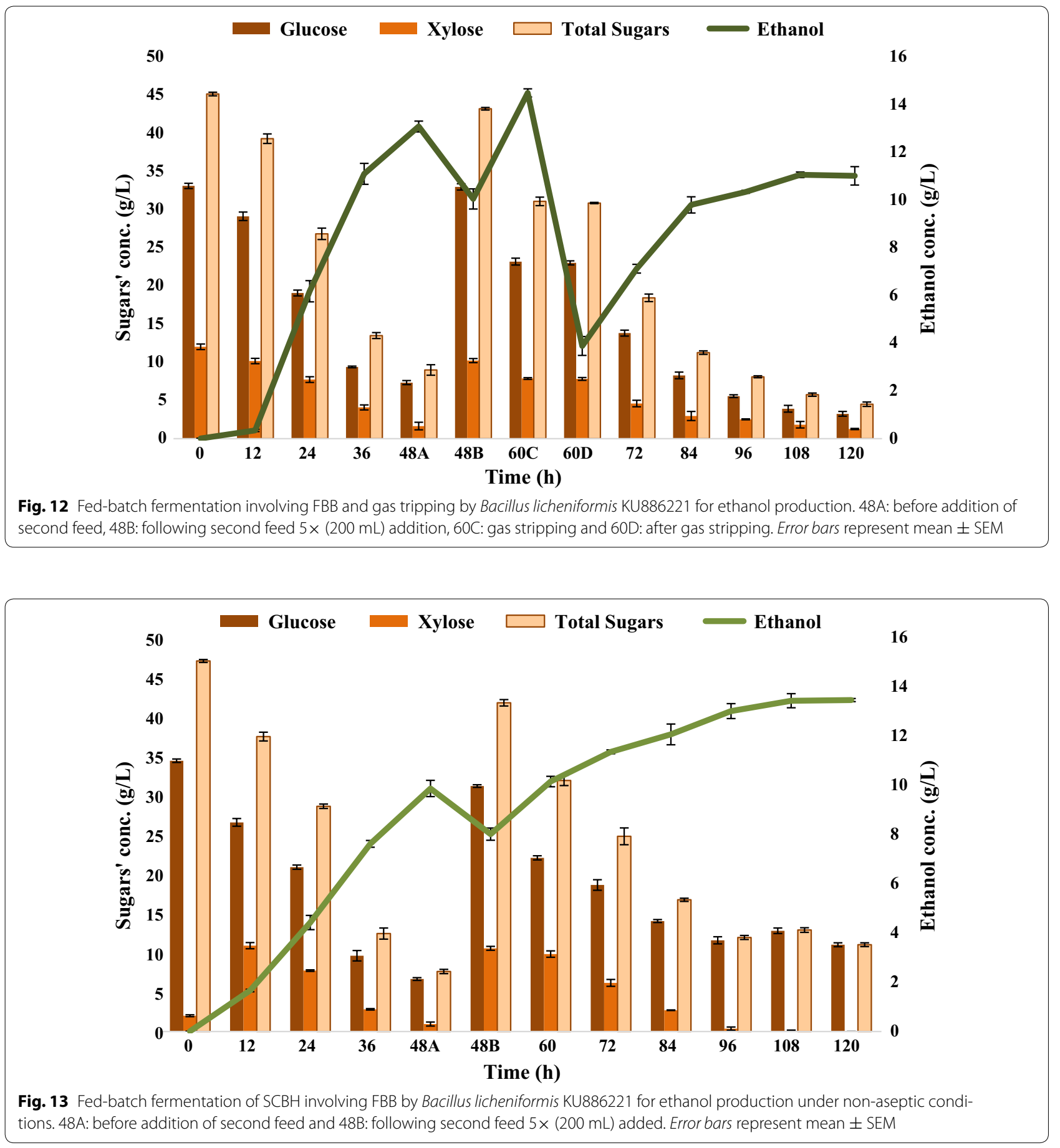

research indicating improved performance in sugar yield after enzymatic hydrolysis of alkaline pretreated SCB, delignification, and biomass utilization, compared to acid pretreatment [33, 34].

When utilization potential of differently pretreated SCB for ethanol production was evaluated, it appeared that ethanol production from B. licheniformis KU886221 was also greater for alkaline pretreated SCB possibly due to less inhibitory compounds' production compared to acid pretreatments that produce more inhibitory compounds for subsequent fermentation processes as reported previously [35]. This is parallel to the previous finding (see Additional file 2) presenting that microbe Saccharomyces cerevisiae was able to yield significantly greater ethanol ( $0.39 \mathrm{~g} / \mathrm{g}$ sugar) employing timothy grass hydrolysate containing $57.4 \mathrm{~g} / \mathrm{L}$ sugar compared to the ethanol yield 


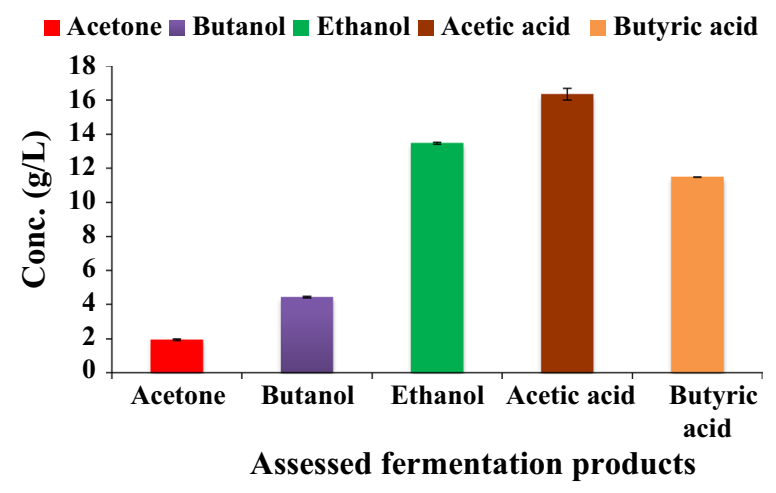

Fig. 14 Fermentation kinetics of Bacillus licheniformis KU886221 (at $120 \mathrm{~h}$ ) of fed-batch fermentation involving FBB under non-aseptic conditions. Error bars represent mean \pm SEM

(0.36 g/g sugar) employing pine wood hydrolysate containing $68.5 \mathrm{~g} / \mathrm{L}$ sugar and wheat straw hydrolysate's ethanol yield ( $0.35 \mathrm{~g} / \mathrm{g}$ hexose) from $63.6 \mathrm{~g} / \mathrm{L}$ sugar [36].

In subsequent experiment, ethanol production was evaluated employing pretreated SCB following enzymatic hydrolysis $(\mathrm{SCBH})$. It was found that ethanol production increased 32.89\% for SCBH. Furthermore, when the bacterium was analyzed to ferment glucose, xylose, and cellulose separately in fermentation medium FM4, it was revealed that after $72 \mathrm{~h}$ of incubation, glucose was the preferred sugar substrate compared to cellulose. It also consumed significant amounts of xylose and mannose. Approximately $60 \%$ reduced ethanol was produced using cellulose directly as substrate in comparison with glucose. Thence, alkaline pretreated SCB hydrolysate was selected as the carbon source in fermentation medium for further investigation.

RSM is an assemblage of statistical performances for scheming experimentations, constructing models, valuing the special effects of experimental factors, and scrutinizing for the optimum conditions facilitating the whole phenomenon. Enzymatic hydrolysis was performed by a combination of two enzymes, i.e., cellulase (Cellic Ctec-2 Novozyme) and hemicellulase (Htec Novozymes) for breaking down biomass to maximum amounts of fermentable sugars. The effect of Ctec and Htec enzymes' quantities on consequent alkaline pretreated SCB hydrolysis for attaining simple fermentable sugars was studied by central composite design.

A quadratic (second-order) polynomial equation was proposed including all interaction terms relating independent and response variables:

$Y=\beta_{0}+\beta_{1} X_{1}^{2}+\beta_{2} X_{2}^{2}+\beta_{3} X_{1}+\beta_{4} X_{2}+X_{1} A X_{2}+\varepsilon$.

The results of the second-order response surface models for the sugar hydrolysis in the form of regression and analysis of variance (ANOVA) were studied under $95 \%$ of confidence interval $(P \leq 0.05)$ and pure error. Desirability profiling with the help of Statistica software enabled to predict enzymes' optimum quantities. After validation of the experiment, enzymes optimum dose was determined as 1.024 g Cellic Ctec Novozymes +0.468 g Htec Novozymes $/ 100 \mathrm{~g}$ of alkaline pretreated SCB that was found to be compliant to the previously investigated [37].

The purpose of the present investigation was to exploit the low-cost substrate for the production of clean and environmentally friendly biofuels. In this regard, corn steep liquor (CSL), a chief by-product of corn starch processing, was used as low-cost nitrogen source. It contains significant amount of proteins, amino acids, vitamins, minerals, and trace elements, and can suitably replace yeast extract and peptone in alcoholic fermentations [38-42]. Specifically, CSL has been reported effective for ethanol fermentations previously [39, 40, 43-45]. In advance experiment, potential of CSL as complex nitrogen source for ethanol production substituting peptone and yeast extract in the fermentation medium was evaluated. It was found that $3.24 \%$ more ethanol was produced when CSL was used in comparison with peptone + yeast extract in the fermentation medium. This increased ethanol production was possibly due to the complex nutritious nature of CSL $[38,40]$.

Concentration of alkaline pretreated SCB hydrolysate, $\mathrm{CSL}$ and $\mathrm{NaCl}$, incubation temperature, $\mathrm{pH}$, and fermentation period were optimized for ethanol fermentation using B. licheniformis KU886221. Experimentation assisted by Taguchi OA experimental design using the Design Expert 8 software enabled us to infer that changing of incubation temperature (optimum: $45{ }^{\circ} \mathrm{C}$ ) and alkaline pH (optimum: 9) are most significant factors affecting ethanol fermentation. Furthermore, a batch culture was carried out under optimized conditions of ethanol fermentation in bench-scale stirred-tank bioreactor. Ethanol yield of $0.909 \mathrm{~mol}$ of ethanol $/ \mathrm{mol}$ of sugars consumed was obtained after $84 \mathrm{~h}$ of incubation, corresponding to $0.279 \mathrm{~g}$ ethanol/g of sugars consumed. Though reduced ethanol yield in comparison with the yield by mesophilic yeast, $S$. cerevisiae (as shown in Additional file 2) was obtained, but the use of thermophilic fermentative bacteria is considered more advantageous where LCB is used as fuels' feed as unlike most mesophilic yeasts, the thermophilic fermentative bacteria are able to ferment hexoses as well as pentoses to ethanol $[36,46]$. The percent reduction of substrate was 98.5 showing significant conversion of substrate into product with ethanol titer of $11.301 \mathrm{~g} / \mathrm{L}$. In terms of biomass, $0.114 \mathrm{~g}$ ethanol/g of alkaline pretreated SCB was yielded. It is noticeable that the slope for ethanol production regarding sugar consumption was nearly 
constant, signifying that this integrated fermentation was very steady and reliable with ethanol as the primarily chief product.

Next, the fed-batch fermentation was performed to understand the influence of substrate addition on batch fermentation. The overall ethanol titer was $16.896 \mathrm{~g} / \mathrm{L}$ associated with $78.94 \%$ substrate consumption. In terms of biomass, $0.123 \mathrm{~g}$ ethanol/g of alkaline pretreated SCB was obtained at the end of fed-batch fermentation experiment. The molar ethanol yield was $0.973 \mathrm{~mol}$ ethanol/ mol sugars consumed. This lower substrate consumption was possibly due to accumulation of inhibitory fermentation metabolites including ethanol.

To lessen the toxic effect of higher density of cells on their further growth/fermentative potential, further adaptation in fed-batch bioreactor was applied by attaching fibrous-bed bioreactor (FBB) to the fermentor $[22,47]$. It is also very innovative fermentation approach to improve solvent tolerance facilitating ethanol fermentation. Increased ethanol production with $85.031 \%$ substrate utilization was observed with $1.076 \mathrm{~mol}$ ethanol/ mol of sugars consumed. In terms of biomass, $0.131 \mathrm{~g}$ ethanol/g of alkaline pretreated SCB was achieved at the end of fermentation. This revealed that immobilizedcell fermentation might be capable of enhancing ethanol production by trapping the cells in fibrous-bed, thus facilitating increased cell tolerance to toxic fermentation metabolites and increase cell viability inside main bioreactor. Ethanol titer was significantly increased from 16.896 to $19.39 \mathrm{~g} / \mathrm{L}$ with the attachment of FBB.

To investigate the ethanol-induced inhibition, further study was done by partially removing ethanol by in situ gas stripping from the fermentation medium. Gas stripping is an established product recovery technique for ABE separation [23, 48-51]. It was confirmed that ethanol intolerance was one of the reasons of growth inhibition. Ethanol titer of $21.637 \mathrm{~g} / \mathrm{L}(1.1406 \mathrm{~mol}$ ethanol $/ \mathrm{mol}$ of sugars consumed) was observed with $94.295 \%$ substrate consumption. Results are compliant with the previous findings that removal of inhibitory compounds leads to a better performance in sugar conversion to products $[48,52]$. Thus, gas stripping is proved to be an effective separation technique used to apprehend synchronized ethanol recovery and overcome product repression due to ethanol-induced inhibition $[52,53]$. In terms of biomass, $0.135 \mathrm{~g}$ ethanol/g of alkaline pretreated SCB was obtained at the end of fed-batch fermentation involving $\mathrm{FBB}$ and gas stripping.

Finally, fed-batch fermentation involving FBB was studied under non-aseptic conditions. The results indicated that $13.466 \mathrm{~g} / \mathrm{L}$ ethanol corresponding $0.570 \mathrm{~mol}$ etha$\mathrm{nol} / \mathrm{mol}$ of sugars consumed was produced at the end of fermentation (at $120 \mathrm{~h}$ ). In terms of biomass, $0.089 \mathrm{~g}$ ethanol/g of alkaline pretreated SCB was obtained. Comparing aseptic conditions, $30.5 \%$ reduced ethanol yield was obtained under non-aseptic conditions showing the likelihood of some contaminant in the fermentation culture. However, cost of sterilization is one of the major obstacles for developing lignocellulosic bio-refineries. Therefore, even a reduced product yield might be considered appealing while saving the cost of sterilization.

In the present study, besides $\mathrm{ABE}$, significant amounts of acetic acid and some butyric acid were also produced during fermentation. ABE were also formed in the condensate after gas stripping. Realizing separation of $\mathrm{ABE}$ along with acetic acid and butyric acid would make the fermentation methodology more efficient as these byproducts are very profitable.

\section{Conclusion}

Purpose of the present investigation was to exploit the locally available lignocellulosic waste for the production of clean and environment friendly energy fuel bioethanol employing extremophiles. In this regard, the bioethanol production by alkali-thermophilic fermentative microbes from bio-waste such as sugarcane bagasse would not only be sustainable, but the extreme conditions will employ a bioprocess for high selection pressure for reducing the likelihood of microbial contaminations. Thus, it will be possible to maintain aseptic environment without spending much for sterilization. Successful exploitation of low-cost substrate for biofuels' production under moderate alkali-thermophilic conditions appeared promising for the development of large-scale bio-fermentation processes. For this purpose, it is extremely important to explore the locally available fermentative ethanologenic thermophiles and understand their metabolic requirements while utilizing lignocellulosic biomass. It is foreseeable that understanding of non-aseptic extremophilic fermentations utilizing agro-industrial waste as necessitated in the present investigation for development of large-scale cost-effective, eco-friendly biofuel generation processes will pave the way to achieve one of the greatest benefits of mankind.

\section{Additional files}

Additional file 1: Figure S1. Desirability profile for predicted values of Ctec and Htec Novozymes for sugarcane bagasse hydrolysis.

Additional file 2: Table S1. Comparison of sugar hydrolysis/ethanol fermentation employing different LCB.

\section{Abbreviations}

LCB: lignocellulosic biomass; SCB: sugarcane bagasse; SCBH: sugarcane bagasse hydrolysate; CSL: corn steep liquor; FBB: fibrous-bed bioreactor; PRS: percentage reduction of substrate; CCD: central composite design; RSM: response surface methodology. 


\section{Authors' contributions}

QA performed all the experimental work, information collection, analysis, and manuscript drafting. STY contributed in bioreactor kinetics study and results interpretation of the experiments performed in Ohio State University, USA. MM contributed in performing statistical analysis of the results. JIQ made substantial contributions to critical discussion and has given final approval of the version to be published. All authors read and approved the final manuscript.

\section{Author details}

${ }^{1}$ Department of Zoology, University of the Punjab, Lahore, Pakistan.

${ }^{2}$ Department of Chemical \& Biomolecular Engineering, Ohio State University, Columbus, OH, USA. ${ }^{3}$ Government College University, Faisalabad, Pakistan.

\section{Acknowledgements}

The first author would like to thank Higher Education Commission of Pakistan for awarding funds under IRSIP for research in Ohio State University, USA and University of the Punjab, Pakistan for providing cost of publication.

\section{Competing interests}

The authors declare that they have no competing interests.

\section{Consent for publication}

All authors have approved the manuscript for submission and confirm that the content of the manuscript has not been published, or submitted for publication elsewhere.

\section{Publisher's Note}

Springer Nature remains neutral with regard to jurisdictional claims in published maps and institutional affiliations.

Received: 24 February 2017 Accepted: 11 April 2017

Published online: 24 April 2017

\section{References}

1. Barnard D, Casanueva A, Tuffin M, Cowan D. Extremophiles in biofuel synthesis. Environ Technol. 2010;31(8-9):871-88.

2. Chandra R, Takeuchi H, Hasegawa T. Methane production from lignocellulosic agricultural crop wastes: a review in context to second generation of biofuel production. Renew Sustain Energy Rev. 2012;16:1462-76.

3. Reddy N, Yang Y. Biofibers from agricultural byproducts for industrial applications. Trends Biotechnol. 2005;23:22-7.

4. Rubin E. Genomics of cellulosic biofuels. Nature. 2008;454:841-5.

5. Huang C, Chen X-F, Xiong L, Chen XD, Ma LL, Chen Y. Single cell oil production from low-cost substrates: the possibility and potential of its industrialization. Biotechnol Adv. 2013;31:129-39.

6. Yang B, Wyman CE. Pretreatment: the key to unlocking low-cost cellulosic ethanol. Biofuel Bioprod Biorefin. 2008:2:26-40.

7. Hu F, Ragauskas A. Pretreatment and lignocellulosic chemistry. Bioenergy Res. 2012:5:1043-66.

8. Martín C, Klinke H, Marcet M, García L, Hernández E, Thomsen AB. Study of the phenolic compounds formed during pretreatment of sugarcane bagasse by wet oxidation and steam explosion. Holzforschung. 2007:61:483-7.

9. Karatzos SK, Edye LA, Doherty WOS. Sugarcane bagasse pretreatment using three imidazolium-based ionic liquids; mass balances and enzyme kinetics. Biotechnol Biofuels. 2012;5:62

10. Rødsrud G, Lersch M, Sjöde A. History and future of world's most advanced biorefinery in operation. Biomass Bioenergy. 2012;46:46-59.

11. Leif JJ, Martín C. Pretreatment of lignocellulose: formation of inhibitory by-products and strategies for minimizing their effects. Bioresour Technol. 2016;199:103-12.

12. Kumar D, Murthy G. Pretreatments and enzymatic hydrolysis of grass straws for ethanol production in the Pacific Northwest US. Biol Eng. 2011;3:97-110.

13. Ren NQ, Zhao L, Chen C, Guo WQ, Cao GL. A review on bioconversion of lignocellulosic biomass to $\mathrm{H} 2$ : key challenges and new insights. Bioresour Technol. 2016;215:92-9.
14. Van Groenestijn JW, Hazewinkel JH, Nienoord M, Bussmann PJ. Energy aspects of biological hydrogen production in high rate bioreactors operated in the thermophilic temperature range. Int J Hydrogen Energy. 2002;27:1141-7.

15. Wernick DG, Pontrelli SP, Pollock AW, Liao J. Sustainable biorefining in wastewater by engineered extreme alkaliphile Bacillus marmarensis. Sci Rep. 2016:6:20224. doi:10.1038/srep20224

16. Chang T, Yao S. Thermophilic, lignocellulolytic bacteria for ethanol production: current state and perspectives. Appl Microbiol Biotechnol. 2011;92(1):13-27

17. Tao L, He X, Tan ECD, Zhang M, Aden A. Comparative techno-economic analysis and reviews of $n$-butanol production from corn grain and corn stover. Biofuels Bioprod Biorefin. 2013;8(3):342-61.

18. Xue C, Zhao J, Chen L, Yang ST, Bai F. Recent advances and state-of-theart strategies in strain and process engineering for biobutanol production by Clostridium acetobutylicum. Biotechnol Adv. 2017;35(2):310-22.

19. Snell FD, Snell CT. Colorimetric methods of analysis. Huntington-NY: Van Nostrand Company Publishing Co; 1961.

20. Nucleotide BLAST-National Institutes of Health. http://www.ncbi.nlm.nih. gov/BLAST/. Accessed 20 Mar 2016.

21. Wen-Hua C, Wen-Heng C, Cheng-Chien L, Wen-Song H. Compositional analysis of biomass feedstocks, Institute of nuclear energy Research Technical Report (INER-4349R) Taiwan 2006.

22. Yang ST. Extractive fermentation using convoluted fibrous bed bioreactor United States Patent Application Publication. US Patent 5563069-A; 1996.

23. Xue C, Zhao JB, Lu CC, Yang ST, Bai FW, Tang I. High-titer $n$-butanol production by Clostridium acetobutylicum JB200 in fed-batch fermentation with intermittent gas stripping. Biotechnol Bioeng. 2012;109:2746-56. doi:10.1002/bit.24563.

24. Lu C, Zhao J, Yang ST, Wei D. Fed-batch fermentation for $n$-butanol production from cassava bagasse hydrolysate in a fibrous bed bioreactor with continuous gas stripping. Bioresour Technol. 2012;104:380-7.

25. Xue C, Zhao J, Liu F, Lu C, Yang ST, Bai F-W. Two-stage in situ gas stripping for enhanced butanol fermentation and energy-saving product recovery. Bioresour Technol. 2013;135:396-402.

26. Li Y, Mandelco L, Wiegel J. Isolation and characterization of a moderately thermophilic anaerobic alkaliphile, Clostridium paradoxum sp. nov. Int J Syst Bacteriol. 1993;43:450-60.

27. Li L, Zhang L, Li K, Wang Y, Gao C, Han B, Xu P. A newly isolated Bacillus licheniformis strain thermophilically produces 2,3-butanediol, a platform and fuel bio-chemical. Biotechnol Biofuels. 2013;6(1):123.

28. Ng TK, Ben-Bassat A, Zeikus JG. Ethanol production by thermophilic bacteria: fermentation of cellulosic substrates by cocultures of Clostridium thermohydrosulfuricum. Appl Environ Microbiol. 1981;41(6):1337-43.

29. Dien BS, Cotta MA, Jeffries TW. Bacteria engineered for fuel ethanol production: current status. Appl Microbiol Biotechnol. 2003;63:258-66.

30. Lynd LR, Currie D, Ciazza N, Herring C, Orem N. Consolidated bioprocessing of cellulosic biomass to ethanol using thermophylic bacteria. In: Wall JD, Harwwod CS, Demain A, editors. Biotechnology part 1, vol. 5. Washington DC: ASM Press; 2008. p. 55-74.

31. Amiri $H$, Karimi K. Efficient dilute-acid hydrolysis of cellulose using solvent pretreatment. Ind Eng Chem Res. 2013;52:11494-501.

32. Zhang YHP, Lynd LR. Toward an aggregated understanding of enzymatic hydrolysis of cellulose: non-complexed cellulase systems. Biotechnol Bioeng. 2004;1996(88):797-824.

33. Guilherme AA, Dantas PVF, Santos ES, Fernandes FAN, Macedo GR Evaluation of composition, characterization and enzymatic hydrolysis of pretreated sugarcane bagasse. Braz J Chem Eng. 2015;32(1):23-33.

34. loelovich M, Morag E. Study of enzymatic hydrolysis of mild pretreated lignocellulosic biomasses. BioResources. 2012;7:1040-52.

35. Kootstra AMJ, Beeftink HH, Scott EL, Sanders JPM. Comparison of dilute mineral and organic acid pretreatment for enzymatic hydrolysis of wheat straw. Biochem Eng J. 2009;46:126-31. doi:10.1016/j.bej.2009.04.020.

36. Nanda S, Dalai AK, Kozinski JA. Butanol and ethanol production from lignocellulosic feedstock: biomass pretreatment and bioconversion. Energy Sci Eng. 2014;2(3):138-48.

37. Kallioinen A, Hakola M, Riekkola T, Repo T, Leskela M, von Weymarn N, Siika-aho M. A novel alkaline oxidation pretreatment for spruce, birch and sugar cane bagasse. Bioresour Technol. 2013;140:414-20. 
38. Amartey S, Jeffries TW. Comparison of corn steep liquor with other nutrients in the fermentation of D-xylose by Pichia stipitis CBS 6054. Biotechnol Lett. 1994;16:211-4.

39. Lawford HG, Rousseau JD. Studies on nutrient requirements and costeffective supplements for ethanol production by recombinant $E$. coli. Appl Biochem Biotechnol. 1996;57-58:307-26.

40. Seo HB, Kim SS, Lee HY, Jung KH. High-level production of ethanol during fed batch ethanol fermentation with a controlled aeration rate and nonsterile glucose powder feeding of Saccharomyces cerevisiae. Biotechnol Bioprocess Eng. 2009;14:591-8.

41. Tang Y, An M, Liu K, Nagai S, Shigematsu T, Morimura S, Kida K. Ethanol production from acid hydrolysate of wood biomass using the flocculating yeast Saccharomyces cerevisiae strain KF-7. Process Biochem. 2006:41:909-14

42. Pereira FB, Guimaraes PM, Teixeira JA, Domingues L. Optimization of lowcost medium for very high gravity ethanol fermentations by Saccharomyces cerevisiae using statistical experimental designs. Bioresour Technol. 2010;101(20):7856-63.

43. Kadam KL, Newman MM. Development of a low-cost fermentation medium for ethanol production from biomass. Appl Microbiol Biotechnol. 1997:47:625-9.

44. Lawford HG, Rousseau JD. Corn steep liquor as a cost-effective nutrition adjunct in high-performance Zymomonas ethanol fermentations. Appl Biochem Biotechnol. 1997;63-65:287-304.

45. Kwon S, Lee PC, Lee EG, Chang YK, Chang HN. Production of lactic acid by Lactobacillus rhamnosus with vitamin-supplemented soybean hydrolysate. Enzyme Microb Technol. 2000;26:209-15.
46. Ahmad Q, Qazi II. Thermophilic fermentations of lignocellulosic substrates and economics of biofuels: prospects in Pakistan. Int J Energy Environ Eng. 2014;5:94.

47. Jiang L, Wang J, Liang S, Wang X, Cen P, Xu Z. Butyric acid fermentation in a fibrous bed bioreactor with immobilized Clostridium tyrobutyricum from cane molasses. Bioresour Technol. 2009;100:3403-9.

48. Park C-H, Okos MR, Wankat PC. Acetone-butanol-ethanol (ABE) fermentation and simultaneous separation in a trickle bed reactor? Biotechnol Prog. 1991;7:185-94.

49. Ezeji TC, Karcher PM, Qureshi N, Blaschek HP. Improving performance of a gas stripping-based recovery system to remove butanol from Clostridium beijerinckii fermentation. Bioprocess Biosyst Eng. 2005;27:207-14.

50. Tong C, Bai Y, Wu J, Zhang L, Yanga L, Qian J. Pervaporation recovery of acetone-butanol from aqueous solution and fermentation broth using HTPB based polyurethane urea membranes. Sep Sci Technol. 2010;45:751-61.

51. Xue C, Liu F, Xu M, Zhao J, Chen L, Ren J, Bai F, Yang ST. A novel in situ gas stripping-pervaporation process integrated with acetone-butanol-ethanol fermentation for hyper $n$-butanol production. Biotechnol Bioeng. 2016;113(1):120-9.

52. Andrew AN. Evaluation of ethanol stripping from fermenters. Master thesis. Imperial College, London, UK; 2010.

53. Chen $\mathrm{HZ}, \mathrm{He} \mathrm{Q}$, Ding WY. Modeling of ethanol separation from continuous solid-state fermentation coupled with online separation by $\mathrm{CO}_{2}$ gas stripping and heat pump technology. J Chem Technol Biotechnol. 2014;90:1897-905.

\section{Submit your next manuscript to BioMed Central and we will help you at every step:}

- We accept pre-submission inquiries

- Our selector tool helps you to find the most relevant journal

- We provide round the clock customer support

- Convenient online submission

- Thorough peer review

- Inclusion in PubMed and all major indexing services

- Maximum visibility for your research

Submit your manuscript at www.biomedcentral.com/submit 